BMC

Genomics

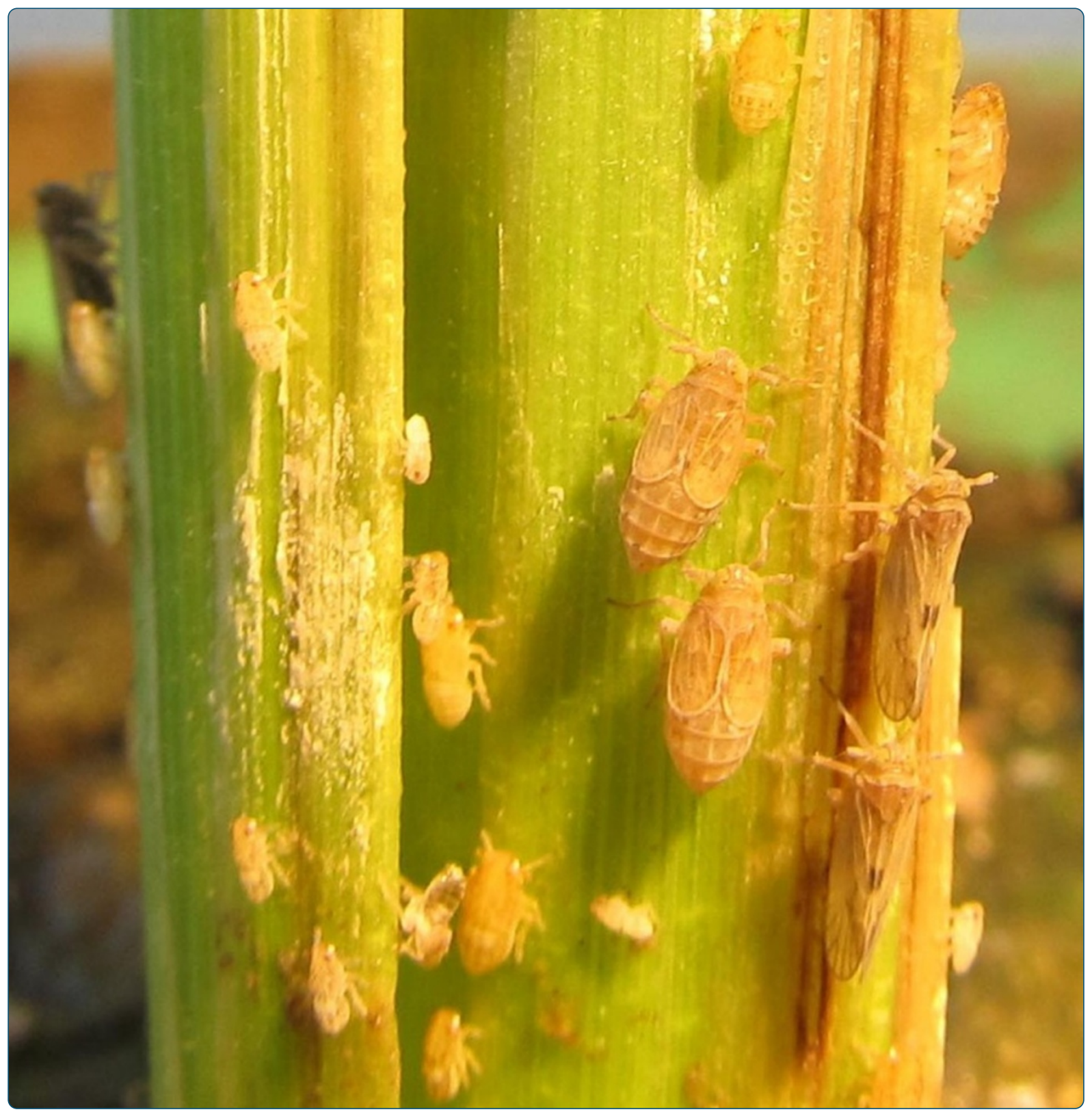

The genome- and transcriptome-wide analysis of innate immunity in the brown planthopper, Nilaparvata lugens

Bao et al. 


\title{
The genome- and transcriptome-wide analysis of innate immunity in the brown planthopper, Nilaparvata lugens
}

\author{
Yan-Yuan Bao, Lv-Yu Qu, Dong Zhao, Li-Bo Chen, Hong-Yuan Jin, Liang-Min Xu, Jia-An Cheng \\ and Chuan-Xi Zhang*
}

\begin{abstract}
Background: The brown planthopper (Nilaparvata lugens) is one of the most serious rice plant pests in Asia. $N$. lugens causes extensive rice damage by sucking rice phloem sap, which results in stunted plant growth and the transmission of plant viruses. Despite the importance of this insect pest, little is known about the immunological mechanisms occurring in this hemimetabolous insect species.

Results: In this study, we performed a genome- and transcriptome-wide analysis aiming at the immune-related genes. The transcriptome datasets include the N. lugens intestine, the developmental stage, wing formation, and sex-specific expression information that provided useful gene expression sequence data for the genome-wide analysis. As a result, we identified a large number of genes encoding $N$. lugens pattern recognition proteins, modulation proteins in the prophenoloxidase (proPO) activating cascade, immune effectors, and the signal transduction molecules involved in the immune pathways, including the Toll, Immune deficiency (Imd) and Janus kinase signal transducers and activators of transcription (JAK-STAT) pathways. The genome scale analysis revealed detailed information of the gene structure, distribution and transcription orientations in scaffolds. A comparison of the genome-available hemimetabolous and metabolous insect species indicate the differences in the immunerelated gene constitution. We investigated the gene expression profiles with regards to how they responded to bacterial infections and tissue, as well as development and sex expression specificity.

Conclusions: The genome- and transcriptome-wide analysis of immune-related genes including pattern recognition and modulation molecules, immune effectors, and the signal transduction molecules involved in the immune pathways is an important step in determining the overall architecture and functional network of the immune components in $\mathrm{N}$. lugens. Our findings provide the comprehensive gene sequence resource and expression profiles of the immune-related genes of $\mathrm{N}$. lugens, which could facilitate the understanding of the innate immune mechanisms in the hemimetabolous insect species. These data give insight into clarifying the potential functional roles of the immune-related genes involved in the biological processes of development, reproduction, and virus transmission in N. lugens.
\end{abstract}

Keywords: Nilaparvata lugens, Hemimetabolous insect, Genome, Transcriptome, Innate immunity, Gene expression

\footnotetext{
* Correspondence: chxzhang@zju.edu.cn

State Key Laboratory of Rice Biology and Ministry of Agriculture Key

Laboratory of Agricultural Entomology, Institute of Insect Sciences, Zhejiang

University, Hangzhou 310058, China
} 


\section{Background}

Insects have a powerful innate immune system with which to defend against pathogenic intruders. Innate immune responses have been well documented in the metabolous insect species, especially in dipteran and lepidopteran insects, as they are important to human health and agricultural production. By contrast, little is known about the immune responses in hemimetabolous insects, despite the fact that their destruction of agricultural crops has become increasingly serious in recent years. Understanding the immune mechanisms of hemimetabolous insects, especially the insect pests, is becoming an urgent requirement.

All phloem-feeding hemipteran insects depend on symbiotic microorganisms to support the necessary nutrition, development, reproduction and defense against natural enemies of their host insects [1,2]. The brown planthopper, Nilaparvata lugens Stål (Hemiptera: Delphacidae), is the most destructive pest for rice throughout Asia. This insect causes extensive rice damage by sucking rice phloem sap and transmitting plant viruses. As a hemimetabolous insect, $N$. lugens is rich in various symbiotic microorganisms, including an intracellular yeast-like symbiont (YLS) and four bacterial microbe phyla, Proteobacteria, Firmicutes, Actinobacteria and Bacteroidete [2]. As the virus vector, N. lugens transmits two plant viruses, the rice ragged stunt virus and rice grassy stunt virus, which result in rice 'grassy stunt' and 'ragged stunt' diseases respectively [3]. In addition, three viruses have been characterized in $N$. lugens, including reovirus, Himetobi $\mathrm{P}$ virus and commensal $\mathrm{X}$ virus [4], and are most likely asymptomatic to host insects. Recently, we have identified a novel nudivirus from $N$. lugens (unpublished). Nudiviruses are a highly diverse group of large, double-stranded circular DNA viruses which are pathogenic for invertebrates [5]. An interesting question arises: how does this insect host maintain a good balance between the symbiotic microorganisms and foreign pathogens? N. lugens is expected to have a precise immune strategy for determining defense strategies against foreign microorganisms or tolerating microbial symbionts.

In our previous study, we obtained a large amount of $N$. lugens transcriptomic datasets using the nextgeneration high-throughput Illumina sequencing, which provided comprehensive gene expression profiles regarding $N$. lugens development (egg, second and fifth instar nymphs), wing dimorphism (macropterous and brachypterous adults) and sex differences (female and male adults) [6], as well as the intestine-specific expression information in $N$. lugens nymphs and adults [7]. More importantly, we first accomplished $N$. lugens whole genomic sequencing and obtained the gene annotation. A thorough search of the $N$. lugens genome sequence, coupled with the transcriptome datasets, generated the detailed immune-related gene information, which included pattern recognition, signal transduction, modulation, and immune responsive effectors. In this report, we first present an overview of the immune-related genes and their expression specificity in hemimetabolous insects. These data may well be helpful in understanding the innate immune mechanisms of $N$. lugens and in establishing their association with insect development, microbial symbionts, and virus transmission.

\section{Results and discussion}

\section{Pattern recognition molecules}

Peptidoglycan recognition protein (PGRP) and $\beta$-glucan recognition protein $(\beta G R P) /$ gram-negative binding protein (GNBP) are two major protein families that sense foreign microbial infection. PGRP was first isolated from hemolymph of the silkworm, as a pattern recognition receptor which binds peptidoglycan (PGN) and triggers prophenoloxidase activating cascade [8]. PGN presents in the cell walls of almost all bacteria, and is a strong elicitor to activate the innate immune response in insects $[9,10]$. The PGRP family is conserved from insects to mammals. These molecules share an approximately 160 amino acid domain (PGRP domain), with similarities to bacteriophage T7 lysozyme, a zinc-dependent $N$ acetylmuramoyl-L-alanine amidase [11-14]. The most highly diversified PGRP homologues have been identified in Drosophila melanogaster [13]. They are expressed as secreted, cytosolic, or transmembrane forms. According to the enzymatic activity, some non-catalytic PGRPs have been implicated in functions as diverse as signaltransducing receptors, positive regulators and effectors [15], while other PGRPs have amidase activity, cleaving lactylamide bonds between the lactyl group of $N$ acetylmuramic acid and the $\alpha$-amino group of the $\mathrm{L}$ alanine residues in the step peptide of PGN to eliminate its immunogenicity, thus down-regulating or turning off the immune response in insects $[12,16,17]$. The amidase type PGRPs conserve the five amino acid residues which coordinate with zinc ions and form a catalytic site in the T7 lysozyme $[17,18]$. However, the receptor-type PGRPs lack some of these residues.

In this study, we identified two PGRP genes by searching the $N$. lugens genome and transcriptome database with the BLASTX algorithm within a cut-off Evalue of $10^{-5}$. The $N$. lugens PGRPs are two long forms that best matched D. melanogaster PGRP-LB and $L C$ (Figure 1). A quintet of active site residues is essential for amidase activity in T7 lysozyme: His-17, Tyr-46, His122, Lys-128 and Cys-130 (Zn-ligands) were conserved in the deduced amino acid sequence of the $N$. lugens PGRP$L B$ (Figure 1A). However, the indispensable active site residues matching His-17 and Cys-130 in the T7 lysozyme 


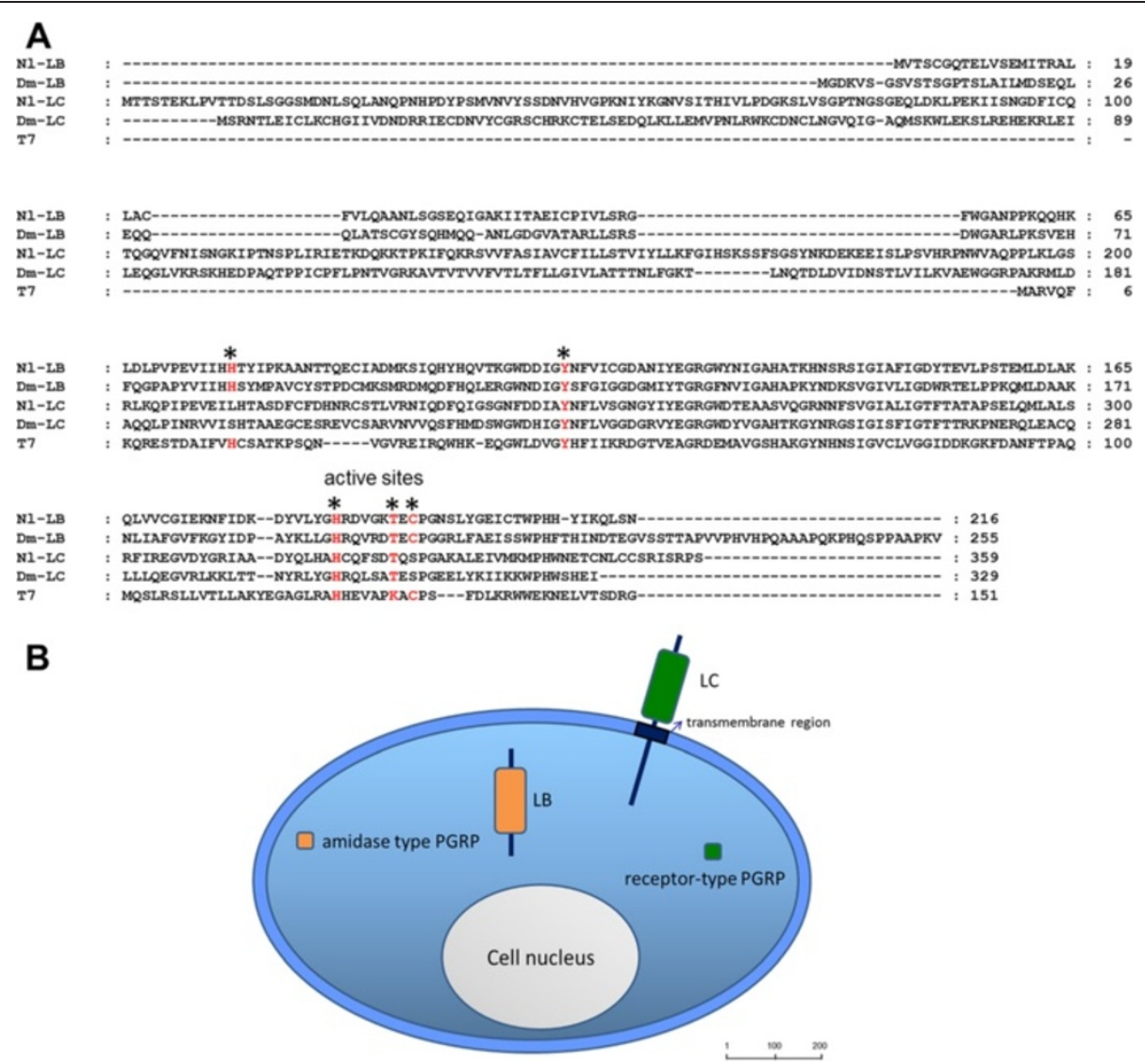

Figure 1 (A) Multiple alignments of PGRPs and T7 lysozyme. The ClustalX program was used for alignments. The GenBank accession numbers for the sequences are as follows: N. lugens PGRP-LB (KC355211); N. lugens PGRP-LC (KC355212); D. melanogaster PGRP-LB (AFH06370); D. melanogaster PGRP-LC (ACZ94668) and Enterobacteria phage T7 lysozyme (AAB32819). Five amino acid residues required for amidase activity are marked by asterisks and shown in red. (B) Predicted cellular distribution of N. lugens PGRPs. N. lugens PGRP-LC is likely a receptor protein due to its transmembrane region. PGRP-LB lacks the signal peptide and transmembrane region, thus possibly making it a cytosolic protein. The potentially catalytic or non-catalytic amidase activity of the PGRP proteins is shown in orange and green respectively. The size bar indicates the amino acid residues of the deduced proteins.

are lacking in the $N$. lugens PGRP-LC. In D. melanogaster, several catalytic PGRPs have been demonstrated (SC1A, SC1B, LB, SB1) or predicted (PGRP-SB2, SC2) amidase activity [12,16,19-21], while PRGP-LC and LE were shown to act as receptors for PGN in the Imd pathway [22]. A prediction of molecular structure implied that $N$. lugens PGRPs are likely to have different functions (Figure 1B). PGRP-LB had neither the signal peptide nor transmembrane region, and thus it probably remains in the cytoplasm. Five active site residues conserved in PGRP-LB imply the potential amidase activity and might serve as an intracellular PGN scavenger. $N$. lugens PGRP-LC may have no amidase activity, due to the incomplete active sites in the predicted amino acid sequence. A transmembrane region was presented in PGRP-LC, suggesting that it may act as a transmembrane-PGN receptor.

We analyzed the bacteria-induced and tissue-specific expression profiles of $N$. lugens PGRP genes. Immune challenges by heat-killed E. coli $\mathrm{K} 12$ and B. subtilis significantly increased $P G R P-L B$ gene expression in $N$. lugens 5th instar nymphs from 6-24 h p.i. PGRP-LC gene expression quickly responded to the $B$. subtilis invasion at $6 \mathrm{~h}$ p.i; while $E$. coli $\mathrm{k} 12$ infection did not significantly increase $P G R P-L C$ expression levels during 6-24 h p.i (Figure 2). PGRP-LB and $L C$ showed very high expression levels in the gut, especially for PGRP-LB, which was exclusively expressed in the gut (Figure $3 \mathrm{~A}$ ). These results suggest that $P G R P-L B$ and $L C$ mainly function in intestinal tracts, a possible route of infection in N. lugens. Among insect PGRPs, direct binding to PGN has been demonstrated for D. melanogaster PGRP-LB and LC [17]. In N. lugens, PGRP-LC may act as a receptor to sense the foreign bacteria that invade the intestinal tract and activate the immune response, while PGRP-LB may be responsible for eliminating the bacteria that enter the cytoplasmic compartment of gut cells. In insect's innate immune systems, Toll and Imd pathways are turned on following the recognition of PGN by PGRPs, while the 
removal of immunostimulatory PGN by PGRPs effectively turns off the excess immune responses. We speculated that $N$. lugens PGRP-LB and LC might work in concert with each other to maintain intestinal immune homeostasis.

GNBP and $\beta$ GRP belong to a pattern recognition receptor family that was initially identified as a component of the proPO-activating cascade in the hemolymph of the silkworm, Bombyx mori [23]. GNBP/ 3 GRP had a strong affinity to $\beta$-1, 3-glucan of fungi and lipopolysaccharide (LPS) of gram-negative bacteria [24,25], but not to the PGN of gram-positive bacteria. Despite not recognizing for PGN, D. melanogaster GNBP1 is required for activating the Toll pathway in response to gram-positive bacterial infections via interaction with PGRP-SA [26,27], while GNBP3 is required to detect fungi and activate the Toll pathway [28]. The GNBP/ $\beta$ GRP family consists of a conserved N-terminal $\beta$-1, 3-glucan-recognition domain and a C-terminal $\beta$-glucanase-like domain $[29,30]$. The $\mathrm{N}$ terminal domain plays a crucial role in the detection of pathogens and the activation of insect host defense responses, while the C-terminal glucanase-like domain has neither glucanase activity nor affinity with $\beta-1,3$-glucan, and as such remains an undefined function [31].

In this study, we identified seven GNBP/ $\beta G R P$ genes in $N$. lugens genome and transcriptome datasets. We designated them as NlGRP1-7. These genes consisted of multiple exons. NlGRP1, 3 and 6 located at the scaffold991 with the same transcription orientations

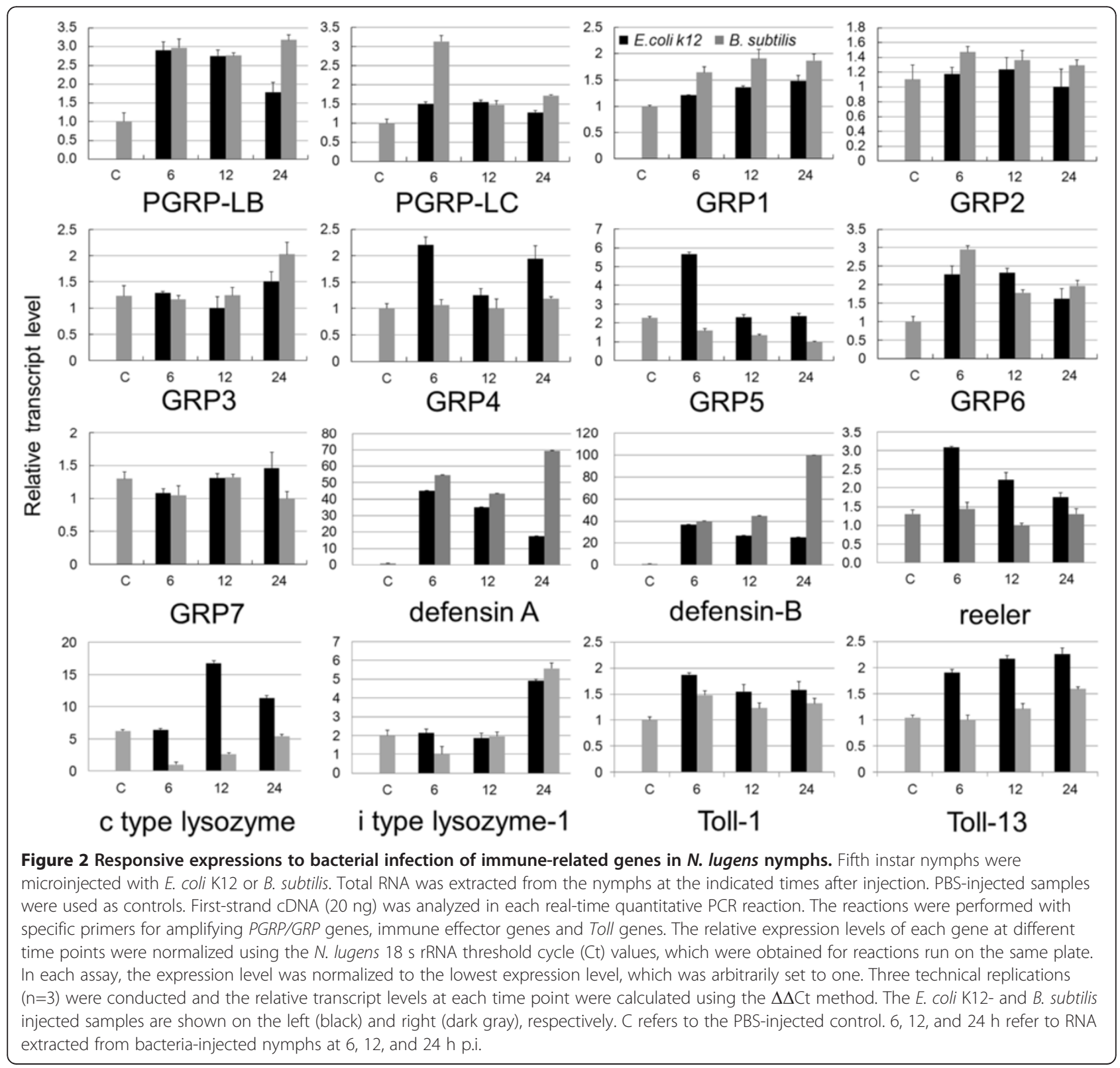




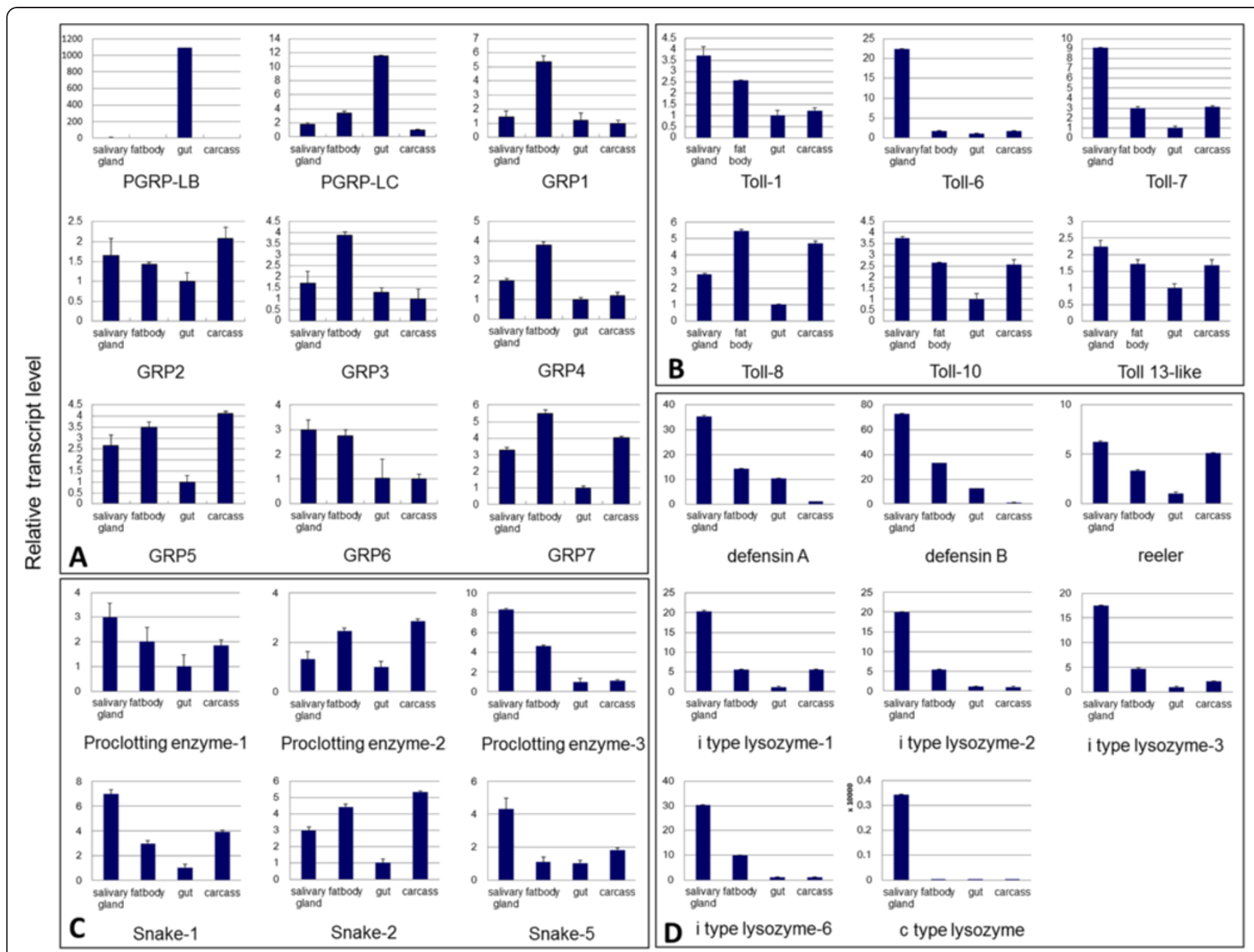

Figure 3 Tissue specificity of immune-related gene expression in $\boldsymbol{N}$. lugens. Total RNA was individually extracted from the salivary gland, fat body, gut and the remaining carcass of 5 th instar nymphs. First-strand CDNA (20 ng) was analyzed in each qRT-PCR reaction. The reactions were performed with specific primers used to amplify (A) PGRP/GRP genes; (B) Toll genes; (C) CLIP genes; and (D) immune effector genes. The relative expression levels of each gene in each tissue were normalized using the $N$. lugens $18 \mathrm{~s}$ rRNA threshold cycle (Ct) values which were obtained from reactions run on the same plate. In each assay, the expression level was normalized to the lowest expression level, which was arbitrarily set at one. Three technical replications $(n=3)$ were conducted and the $\Delta \Delta C t$ method was used to measure the relative transcript levels in tissues.

(Figure 4A \& Table 1). A thorough search of the N. lugens transcriptome coupled with the RACE method revealed that six genes (NlGRP1-6) contained the complete coding regions with the putative signal peptide sequences, implying the secreted proteins (Figure 4B). NlGRP7 had no signal peptide due to a lack of sequence at the $5^{\prime}$ end. A comparison of the deduced amino acid sequences with $D$. melanogaster GNBP1 showed that NlGRP1-3 contained the putative $\mathrm{N}$-terminal $\beta$-1, 3-glucan-recognition domain and the C-terminal glucanase-like domain. NlGRP4 and 5 lacked the $\mathrm{N}$-terminal $\beta-1,3$-glucan-recognition domain, possibly suggesting that they do not directly bind $\beta-1$, 3-glucan. By contrast, NlGRP6 lacked the C-terminal glucanase-like domain. However, the presence of the putative N-terminal $\beta$-1, 3-glucan-recognition domain implied its role in the recognition of pathogens. The deduced protein sequences of the NlGRP1-3 consisted of 499-579 amino acids and showed around $60 \%$ of sequence similarities with $\beta$-GRP of Rhodnius prolixus, while NlGRP4 and 5 contained approximately 360 amino acid residues, which had 57\% sequence similarities with GNBP3 of Locusta migratoria. By contrast, NlGRP6 encodes a small peptide that is composed of 156 amino acids and which showed $64 \%$ similarity with $\beta-1,3$-glucan recognition protein of Bombyx mori. The N-terminal $\beta$-1, 3-glucan-recognition domain was studied rigorously in $D$. melanogaster and $B$. mori. Recently, the secondary structure of the N-terminal domain of B. mori GRP was reported, and was found to comprise eight $\beta$-strands which specifically recognize $\beta-1$, 3 -glucan [31]. A comparison of the $\mathrm{N}$-terminal domains revealed high sequence similarities among the deduced $N$. lugens, D. melanogaster and B. mori homologues (Figure 5), suggesting the possible ability of these $N$. lugens GRPs to bind to fungal $\beta-1,3$-glucan. 


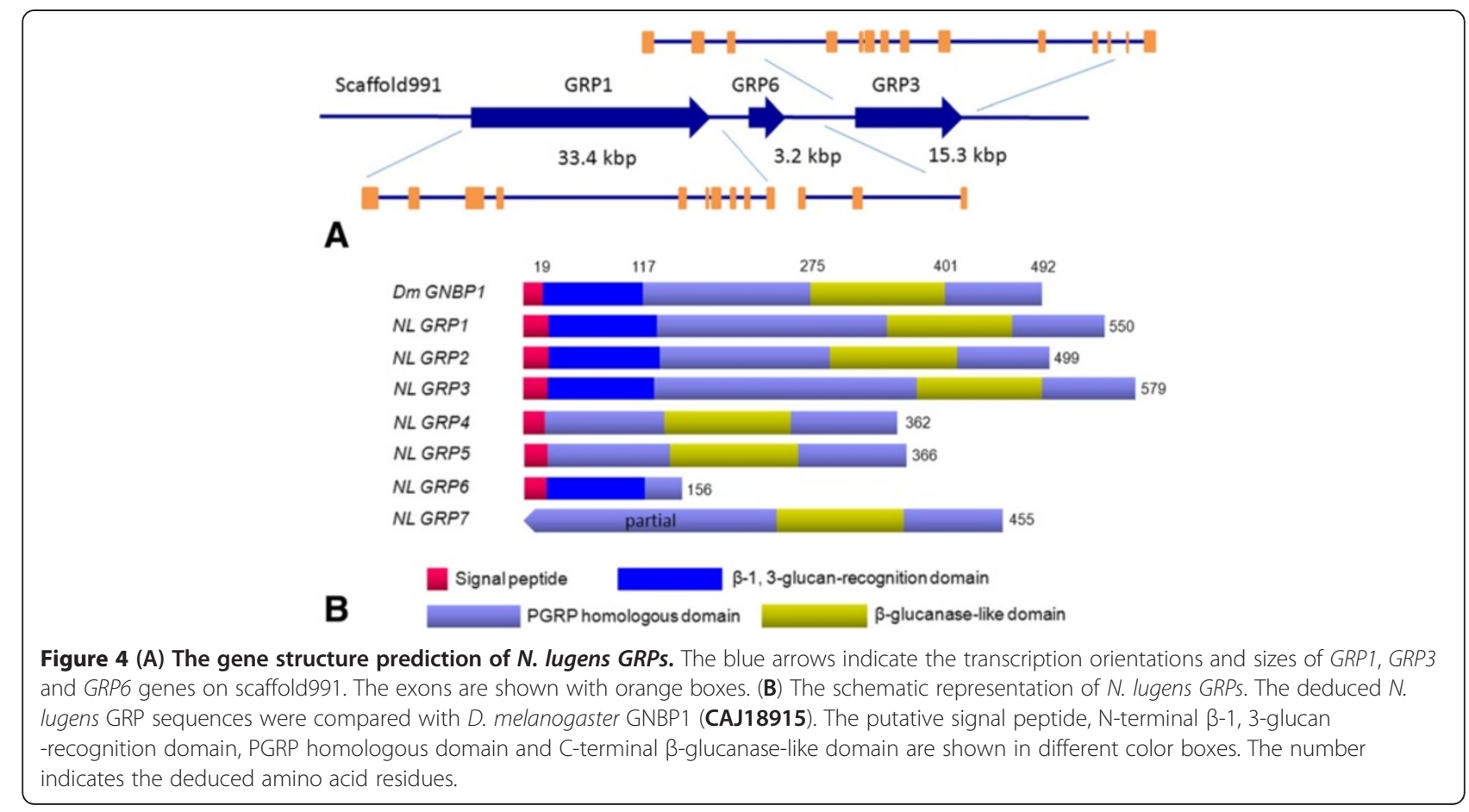

We investigated the $N$. lugens $G R P$ gene expressions upon bacterial infection. Their expressions were differentially affected by gram-positive and negative bacteria species. Among these genes, GRP5 expression was significantly up-regulated following E. coli $\mathrm{K} 12$ challenge at $6 \mathrm{~h}$ p.i, and returned to the level of control during 12-24 h p.i, whereas B. subtilis was not able to increase its expression (Figure 2). Similarly, E. coli K12 up-regulated GRP4 gene expression at $6 \mathrm{~h}$ p.i, although it was not significant, much like the variation of GRP5 gene expression. The fact that E. coli K12-induced expressions appeared at the early infection stage suggests that GRP4 and GRP5 genes responded quickly to gram-negative bacterial infection. Despite the $\beta$-1, 3-glucan-recognition domain not being conserved in the $\mathrm{N}$-terminal end of these two genes, we could not exclude the possibility that they interact with gram-negative bacteria in the $\mathrm{N}$ terminal domain-independent manner. The expression of another gene, GRP6, was strongly increased by both $E$. coli $\mathrm{K} 12$ and B. subtilis from $6 \mathrm{~h}$ p.i, before it gradually decreased to $24 \mathrm{~h}$ p.i. This indicated that this gene expression is responsive to both gram-negative and positive bacterial infection, and may be involved in the recognition of distinct types of bacteria in innate immune responses. GRP1 gene expression was gradually increased upon E. coli $\mathrm{K} 12$ and $B$. subtilis injection from $6 \mathrm{~h}$ p.i. The other GRP gene

Table 1 The gene prediction of $\boldsymbol{N}$. lugens pattern recognition molecules

\begin{tabular}{|c|c|c|c|c|c|c|c|c|c|c|}
\hline Predicted gene & GenBank ID & Locus & Size (aa) & Exon & Orientation & UTR & Best match & Similarity & $\mathrm{Mw}(\mathrm{KDa})$ & $\mathrm{pl}$ \\
\hline$P G R P-L B$ & KC355211 & scaffold1556 & 216 & 3 & - & no & D. melanogaster & $58 \%$ & 24.01 & 6.03 \\
\hline PGRP-LC & KC355212 & scaffold1031 & 359 & 3 & - & no & D. melanogaster & $59 \%$ & 39.51 & 7.12 \\
\hline GRP1 & KC355197 & scaffold991 & 550 & 10 & + & no & L. migratoria & $51 \%$ & 62.34 & 5.44 \\
\hline GRP2 & KC355198 & scaffold5509 & 499 & 6 & + & no & R. prolixus & $57 \%$ & 56.70 & 6.84 \\
\hline GRP3 & KC355199 & scaffold991 & 579 & 14 & + & no & R. prolixus & $60 \%$ & 65.83 & 5.69 \\
\hline GRP4 & KC355200 & scaffold2822 & 362 & 11 & - & no & L. migratoria & $57 \%$ & 41.89 & 5.97 \\
\hline GRP5 & KC355201 & scaffold1504 & 366 & 9 & - & no & L. migratoria & $57 \%$ & 42.15 & 5.01 \\
\hline GRP6 & KC355202 & scaffold991 & 156 & 3 & + & no & B.mori & $64 \%$ & 17.64 & 5.29 \\
\hline GRP7 (partial) & KC355203 & scaffold412 & 455 & 16 & + & no & R. prolixus & $58 \%$ & 51.44 & 6.42 \\
\hline
\end{tabular}

The genomic organization of exons and introns of the genes for pattern recognition proteins is predicted based on the mRNA-genome alignments at the NCBI spideyweb (http://www.ncbi.nlm.nih.gov/spidey/spideyweb.cgi). PGRP: Peptidoglycan recognition protein; GRP: $\beta$-glucan recognition protein. Locus, size and orientation indicate the location on scaffold, predicted amino acids (aa) and the transcription orientation of the genes. UTR: Untranslated regions. Molecular weight $(\mathrm{Mw})$ and isoelectric point ( $\mathrm{pl}$ ) are analyzed using Compute pl/MW tool (http://web.expasy.org/compute_pi/). D. melanogaster, Drosophila melanogaster; L. migratoria, Locusta migratoria; R. prolixus, Rhodnius prolixus; B.mori, Bombyx mori. 

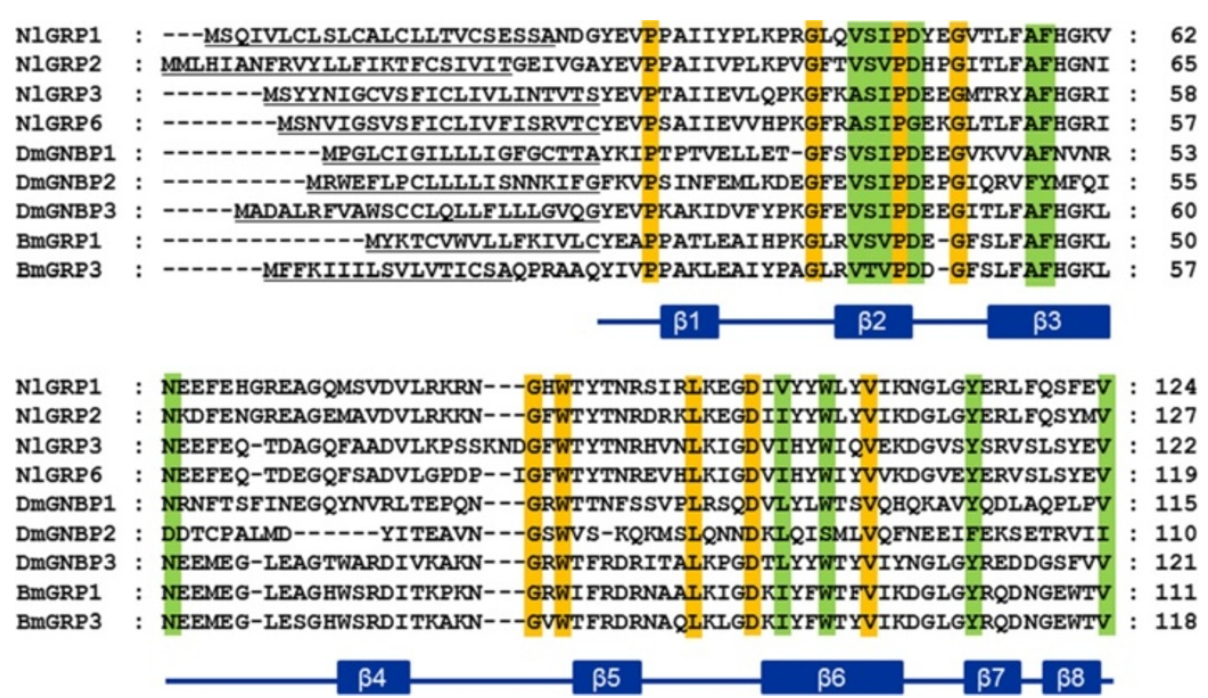

Figure 5 Alignments of the N-terminal domains of GNBP/GRPs. The deduced amino acid sequences of N. lugens GRPs were compared with D. melanogaster GNBP1 (CAJ18915), GNBP2 (CAJ19023), GNBP3 (AF228474), B. mori GRP1 (BAA92243) and GRP3 (BAG70413). The putative signal peptides are underlined. The amino acids in orange and green shade indicate the conserved and type-conserved residues, respectively. The predicted secondary structural elements of eight $\beta$-strands are shown below the alignments. DmGNBP, D. melanogaster gram-negative bacteria binding proteins; BmGRP, B. mori $\beta$-1, 3-glucan recognition protein.

expressions were not significantly induced by bacteria challenges. These results suggested that $N$. lugens GRPs probably have selective affinity with different bacteria and this leads to antibacterial responses in $N$. lugens. Tissue specificity showed that $N$. lugens GRP1-7 genes have low expression levels in the gut (Figure 3A), but high levels in fat body; an important immune tissue in insects. This implies that $N$. lugens GRPs contribute to defense responses against bacteria in this tissue. Some genes, namely GRP2, 5 and 7 also showed high expression levels in the salivary gland and carcass including head and epidermal tissues, suggesting these GRPs may play important roles in these tissues.

\section{Immune signaling pathway-related molecules}

In insects, Toll and Imd pathways are the major innate immune signaling pathways that sense microbes in hemolymph [32]. The Toll pathway is primarily involved in the defense against fungi and gram-positive bacteria with lysine-type peptidoglycans (Lys-type PGNs) in their cell walls, while the Imd pathway responds to gramnegative bacteria and some gram-positive bacteria with meso-di-aminopimelic acid-type peptidoglycan (Dap-type PGNs), namely Bacillus [33]. The activation of the Toll pathway takes place via the binding of an extracellular ligand, Spatzle to the transmembrane receptor Toll, which triggers an intracellular signaling cascade, including the adaptor proteins $\mathrm{dMyD} 88$ and Tube, while the kinase Pelle leads to the proteolytic degradation of the I- $k B$ like inhibitor Cactus and the nuclear import of the NF- $\mathrm{kB}$ like transcription factors Dorsal and Dif [34,35]. In the Imd pathway, a transmembrane protein PGRP-LC, is the signal receptor that triggers an intracellular signaling transduction, including Imd, Fas-associated death domain protein (FADD), Dredd, IAP2, transforming growth factor $\beta$ activated kinase (TAK1), Tab2, Ubc13, and an inhibitor of nuclease factor $\kappa B$ kinase subunits $\beta$ and $\gamma$ (IKK $\beta$ and $\mathrm{IKK} \gamma$ ). This results in the activation and nuclear translocation of an NF- $\mathrm{kB}$ like transcription factor, Relish [25]. Toll and Imd pathways ultimately regulate the microbeinduced gene expressions including various humoral immune factors, namely antibacterial peptides.

The Toll receptor, as the signal transducer of the Toll pathway, plays a crucial role in insect innate immune response and embryogenesis; that is, in the establishment of dorsal-ventral polarity in the early embryo [36]. A typical Toll receptor generally contains extracellular leucine-rich repeats (LRRs) connected to a cysteine-rich domain and an intracytoplasmic Toll-interleukin homolog domain (TIR) [37]. In this study, we identified six genes coding Toll receptors in $N$. lugens genome and transcriptome datasets. These genes were designated as $N$. lugens Toll-1, Toll-6, Toll-7, Toll-8, Toll-10 and Toll-13 because of their deduced amino acids showing significant sequence similarities with their insect counterparts. The predicted proteins, with the exception of the Toll-13 like protein, consist of the extracellular LRR, transmembrane and cytoplasmic TIR domains (Figure 6A). N. lugens Toll13 like gene sequence was obtained from both of the predicted genomic CDS and transcriptome datasets which 
showed the identical coding sequence, and whose deduced protein lacked the transmembrane region and the conserved TIR domain, but had a putative signal peptide sequence. This suggests that it is a secrete-type protein. $N$. lugens genome information predicted that the Toll-13 like gene contains two exons flanked by the $5^{\prime}$ and $3^{\prime}$ untranslated regions (UTR5 and UTR3), indicating a complete coding sequence (Figure 6A). An additional $3^{\prime}$ RACE experiment confirmed that the Toll-13 like gene contains

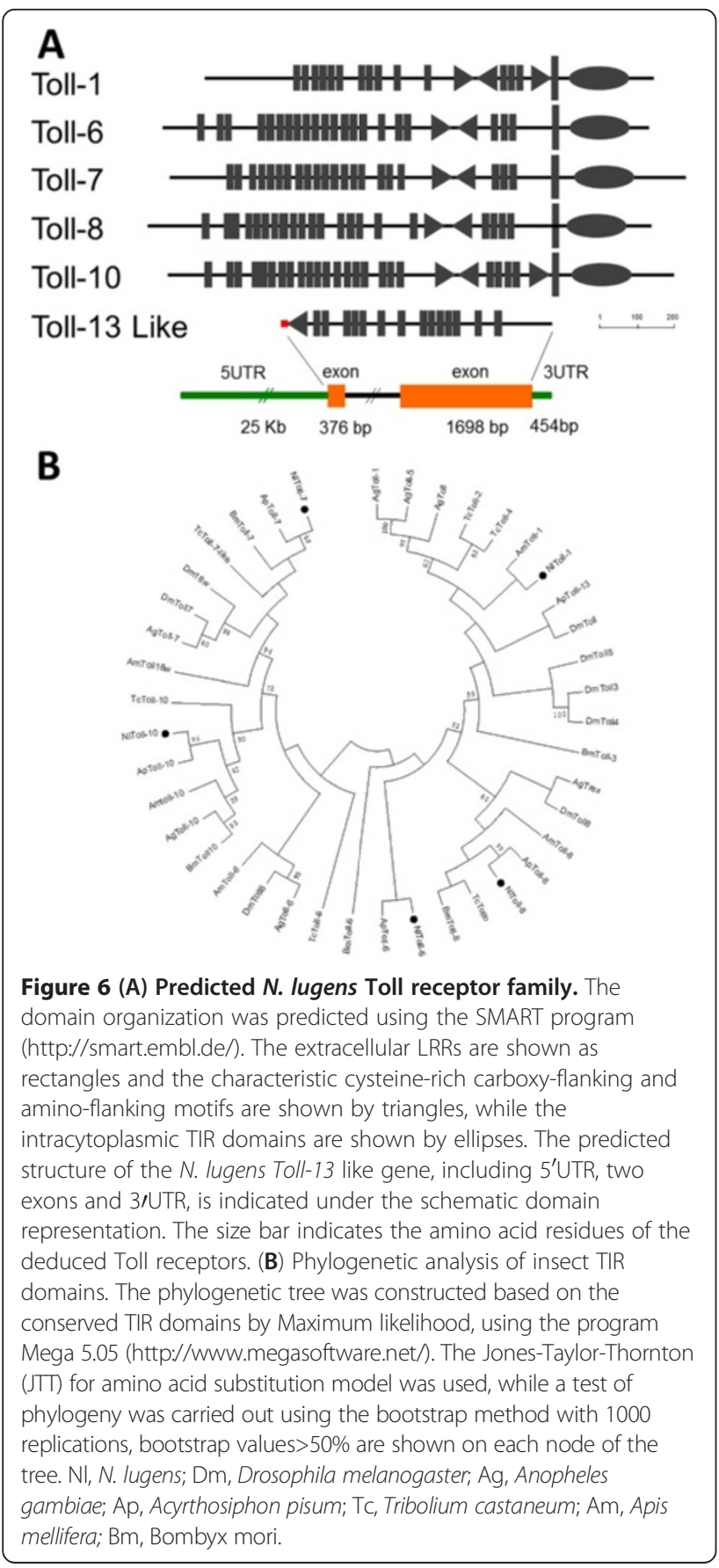

the full-length encoding sequence. $N$. lugens Toll genes are located in different scaffolds (Table 2). Toll-7 and Toll10 are intronless, while Toll-1, Toll-8, Toll-6, and Toll-13 like genes contain six, three, two, and two exons respectively.

The TIR domain is highly conserved in insect and mammalian Toll families and has a more reliable determination of phylogeny than the extracellular LRR regions [38]. With this in mind, we constructed a phylogenetic tree with the TIR domains using the program Mega 5.05 (http://www.megasoftware.net/). The result showed that insect Toll receptors analyzed in this study form five major clusters, Toll-1-5, Toll-6, Toll-7, Toll-8, and Toll-10 (Figure 6B). N. lugens Tolls are distributed in each cluster and are closely related to Apis mellifera Toll-1, Acyrthosiphon pisum Toll-6, Toll-7, Toll-8, and Toll-10, individually, suggesting that most $N$. lugens Tolls have the most closely phylogenetic relationship with those counterparts from A. pisum.

We investigated Toll gene expressions upon bacterial infection. E. coli $\mathrm{K} 12$ significantly increased the transcript levels of Toll-1 and Toll-13 genes, while B. subtilis slightly increased their transcript levels during 6-24 h p. i (Figure 2), suggesting that these two Toll receptors responded to the E. coli $\mathrm{K} 12$ challenge. Bacteria injection did not change Toll-6, Toll-7, Toll-8, and Toll-10 gene expressions (data not shown).

$N$. lugens Toll genes showed distinct tissue-specific expression patterns in the 5th instar nymphs (Figure 3B). Their transcripts, with the exception of Toll 8, were detected at high levels in the salivary gland. Toll 6 exhibited an exclusive expression in the salivary gland among the test tissues. Toll 1, Toll 7, Toll 10, and Toll 13 genes also had the significantly high expression levels in the salivary gland, followed by the fat body and carcass. Toll 8 gene expression is somehow different, with transcripts detected at high levels in the fat body, followed by the carcass.

\section{Signaling modulation-related molecules}

Prophenoloxidase (proPO) activation cascade is one of the major innate immune responses in arthropods, and is similar to the blood clotting system and the complement system of vertebrates. This cascade initiates the binding of pattern recognition proteins to microbederived molecules, such as LPS, $\beta-1,3$-glucan and PGN, which triggers a serine protease cascade in the hemolymph [39]. The final step in this cascade is the conversion of inactive proPO to active phenoloxidase (PO) by clip-domain serine proteases, which leads to melanization responses for the removal of invaded pathogens [40]. In arthropods, clip-domain serine proteases (CLIPs) play an important role in mediating innate immunity, namely proPO activation cascade, hemolymph clotting and 
Table 2 The genomic prediction of $\mathbf{N}$. lugens Toll family

\begin{tabular}{|c|c|c|c|c|c|c|c|c|c|c|c|c|}
\hline $\begin{array}{l}\text { Predicted } \\
\text { gene }\end{array}$ & GenBank ID & Locus & $\begin{array}{l}\text { Size } \\
\text { (aa) }\end{array}$ & Exon & Orientation & UTR & $\begin{array}{l}\text { LRR } \\
\text { region }\end{array}$ & $\begin{array}{c}\text { Transmemebraneand } \\
\text { LIR }\end{array}$ & Best match & Similarity & $\begin{array}{c}\mathrm{Mw} \\
(\mathrm{KDa})\end{array}$ & pl \\
\hline Toll-1 & KC355234 & scaffold1767 & 1156 & 6 & - & no & 14 & have & P. h. corporis & $61 \%$ & 131.3 & 6.16 \\
\hline Toll-6 & KC355235 & scaffold 1818 & 1254 & 2 & - & no & 21 & have & T. castaneum & $85 \%$ & 142.5 & 5.86 \\
\hline Toll-7 & KC355236 & scaffold 1910 & 1325 & 1 & + & no & 21 & have & P. h. corporis & $79 \%$ & 150.8 & 6.06 \\
\hline Toll-8 & KC355237 & scaffold90 & 1296 & 3 & + & no & 21 & have & P. h. corporis & $81 \%$ & 147.7 & 5.48 \\
\hline Toll-10 & KC355238 & scaffold569 & 1302 & 1 & + & no & 23 & have & P. h. corporis & $73 \%$ & 146.4 & 5.57 \\
\hline Toll-13 & KC355193 & scaffold2123 & 691 & 2 & - & have & 14 & no & A. mellifera & $67 \%$ & 77.13 & 5.22 \\
\hline
\end{tabular}

The genomic organization of exons and introns of the genes for pattern recognition proteins is predicted based on the mRNA-genome alignments at the NCBI spideyweb (http://www.ncbi.nlm.nih.gov/spidey/spideyweb.cgi). LRR: leucine-rich repeats; TIR: Toll-interleukin homolog domain. Molecular weight (Mw) and isoelectric point (pl) are analyzed using Compute pl/MW tool (http://web.expasy.org/compute_pi/). P. h. corporis, Pediculus humanus corporis; T. castaneum, Tribolium castaneum; A. mellifera, Apis mellifera.

embryonic development [41]. CLIPs feature at least one regulatory clip domain at the amino-terminus, and a catalytic serine protease domain at the carboxyl-terminus $[42,43]$. Each clip domain contains six conserved cysteine residues which form three disulfide linkages.

Thus far, only one gene encoding CLIP (GenBank accession no. AJ852425) has been isolated from $N$. lugens. In this study, we identified twelve CLIPs by searching the $N$. lugens genomic and transcriptomic sequences. These genes distribute at seven scaffolds and their deduced amino acid sequences contain a clip domain at the $\mathrm{N}$-terminus and a serine protease domain at the $\mathrm{C}$ terminus (Table 3). Of these genes, five encode proclotting enzymes (Nlproclotting enzyme1-5) and seven encode serine protease snake-like proteins (Nlsnake1-7). The genome structure prediction showed

Table 3 The genomic prediction of $\boldsymbol{N}$. lugens clip-domain serine proteases and serine protease inhibitors

\begin{tabular}{|c|c|c|c|c|c|c|c|c|}
\hline Predicted gene & GenBank ID & Locus & Size (aa) & Exon & Orientation & UTR & Best match & Similarity \\
\hline \multicolumn{9}{|c|}{ Clip domain serine proteases } \\
\hline proclotting enzyme-1 & KC355213 & scaffold424 & 397 & 7 & + & no & A.pisum & $56 \%$ \\
\hline proclotting enzyme-2 & KC355214 & scaffold424 & 376 & 11 & - & no & A.pisum & $55 \%$ \\
\hline proclotting enzyme-3 & KC355215 & scaffold1854 & 460 & 9 & - & have & A.pisum & $66 \%$ \\
\hline proclotting enzyme-4 & KC355216 & scaffold32 & 535 & 8 & + & no & A.pisum & $62 \%$ \\
\hline proclotting enzyme-5 & KC355217 & scaffold973 & 264 & 5 & + & no & D.plexippus & $68 \%$ \\
\hline serine protease snake-1 & KC355219 & scaffold407 & 363 & 7 & + & have & A.pisum & $54 \%$ \\
\hline serine protease snake-2 & KC355220 & scaffold183 & partial & 5 & - & no & T. castaneum & $51 \%$ \\
\hline serine protease snake-3 & KC355221 & scaffold183 & partial & 7 & - & no & A.pisum & $47 \%$ \\
\hline serine protease snake-4 & KC355222 & scaffold3538 & 546 & 7 & + & no & P. h.corporis & $58 \%$ \\
\hline serine protease snake-5 & KC355223 & scaffold407 & 358 & 8 & - & no & A.pisum & $41 \%$ \\
\hline serine protease snake-6 & KC355224 & scaffold407 & 378 & 8 & - & no & A.pisum & $45 \%$ \\
\hline serine protease snake-7 & KC355225 & scaffold407 & 362 & 6 & - & no & A.pisum & $53 \%$ \\
\hline \multicolumn{9}{|c|}{ Serine protease inhibitors } \\
\hline serpin-1 & KC355226 & scaffold2106 & partial & 8 & + & no & C. suppressalis & $69 \%$ \\
\hline serpin-2 & KC355239 & scaffold1141 & 402 & 5 & + & have & A.gambiae & $55 \%$ \\
\hline serpin-3 & KC355227 & scaffold690 & 400 & 5 & + & have & T. castaneum & $53 \%$ \\
\hline serpin-4 & KC355228 & scaffold1199 & 408 & 8 & - & no & A.pisum & $60 \%$ \\
\hline serpin-5 & KC355229 & scaffold914 & 492 & 7 & - & no & B. mori & $73 \%$ \\
\hline serpin-6 & KC355230 & scaffold3763 & partial & 11 & - & no & C. quinquefasciatus & $62 \%$ \\
\hline serpin-7 & KC355231 & scaffold1822 & 505 & 4 & + & no & A.pisum & $57 \%$ \\
\hline serpin-8 & KC355232 & scaffold1121 & partial & 4 & + & no & A.pisum & $83 \%$ \\
\hline serpin-9 & KC355233 & scaffold1452 & partial & 5 & - & no & A.pisum & $64 \%$ \\
\hline
\end{tabular}


that a pair of genes, Nlproclotting enzyme 1 and 2 (GenBank accession no. KC355213 and KC355214), were located at the scaffold424 and had the opposite transcription orientations, as well as containing 7 and 11 exons respectively (Figure 7A). Their deduced amino acids shared $67 \%$ and $97 \%$ sequence similarities with the known $N$. lugens CLIP (GenBank accession no. AJ852425). Similarly, two CLIP genes, Nlsnake2 and snake3 (GenBank accession no. KC355220 and KC355221) were located at the scaffold183, and had the same transcription orientations (Figure 7B). They consisted of 5 and 7 exons, which were flanked by two serine protease genes without the clip-domain. In addition, four CLIP genes were located at the scaffold 407. Snake1 gene (GenBank accession no. KC355219) includes 7 exons flanked by the $5^{\prime}$ and $3^{\prime}$ UTRs. Snake5-

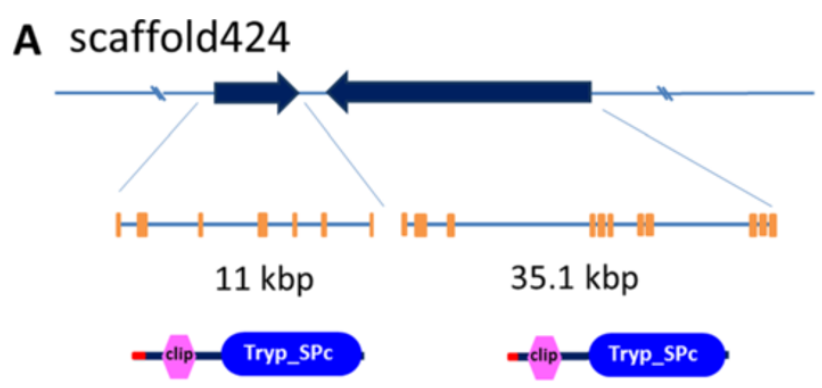

$\mathrm{NI}$ proclotting enzyme-1 NI proclotting enzyme-2

B scaffold183

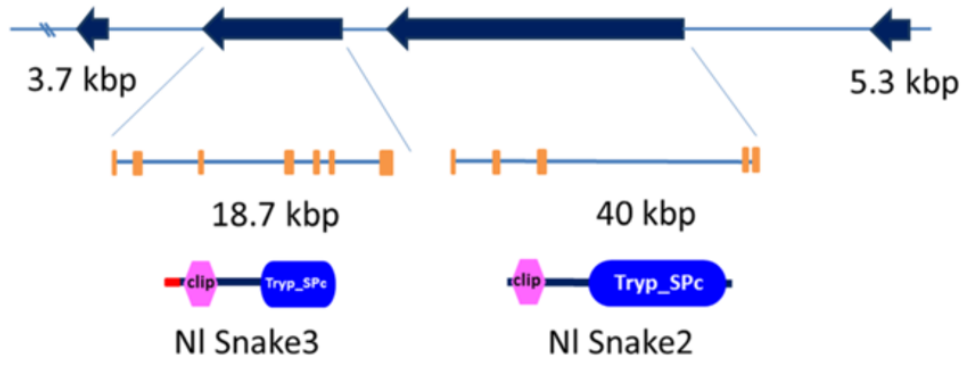

C scaffold 407

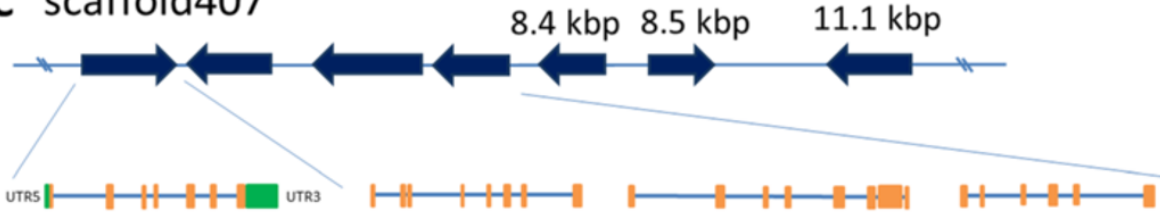

$12.6 \mathrm{kbp}$

Tryp_SPc

NI Snake1

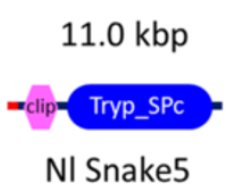

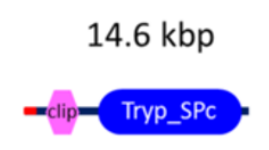

NI Snake6
$10.6 \mathrm{kbp}$

Tryp_SPC

NI Snake7

Figure 7 Structure and location of N. lugens CLIP genes on scaffolds. (A) proclotting enzyme-1 and proclotting enzyme-2 genes; (B) snake-2 and snake-3 genes; (C) snake-1 and snake5-7 genes. The black arrows indicate the transcription orientations and gene sizes on scaffolds. The exons are shown with orange boxes. The schematic representation of the deduced CLIP structures is shown in the panel below. Red bars, hexagons, and oblongs indicate the putative signal peptide sequence, clip domain, and serine protease domain, respectively. The small black arrows flanking the CLIP genes are serine proteases without clip-domains. The size bar indicates the amino acid residues of the deduced CLIPS. 


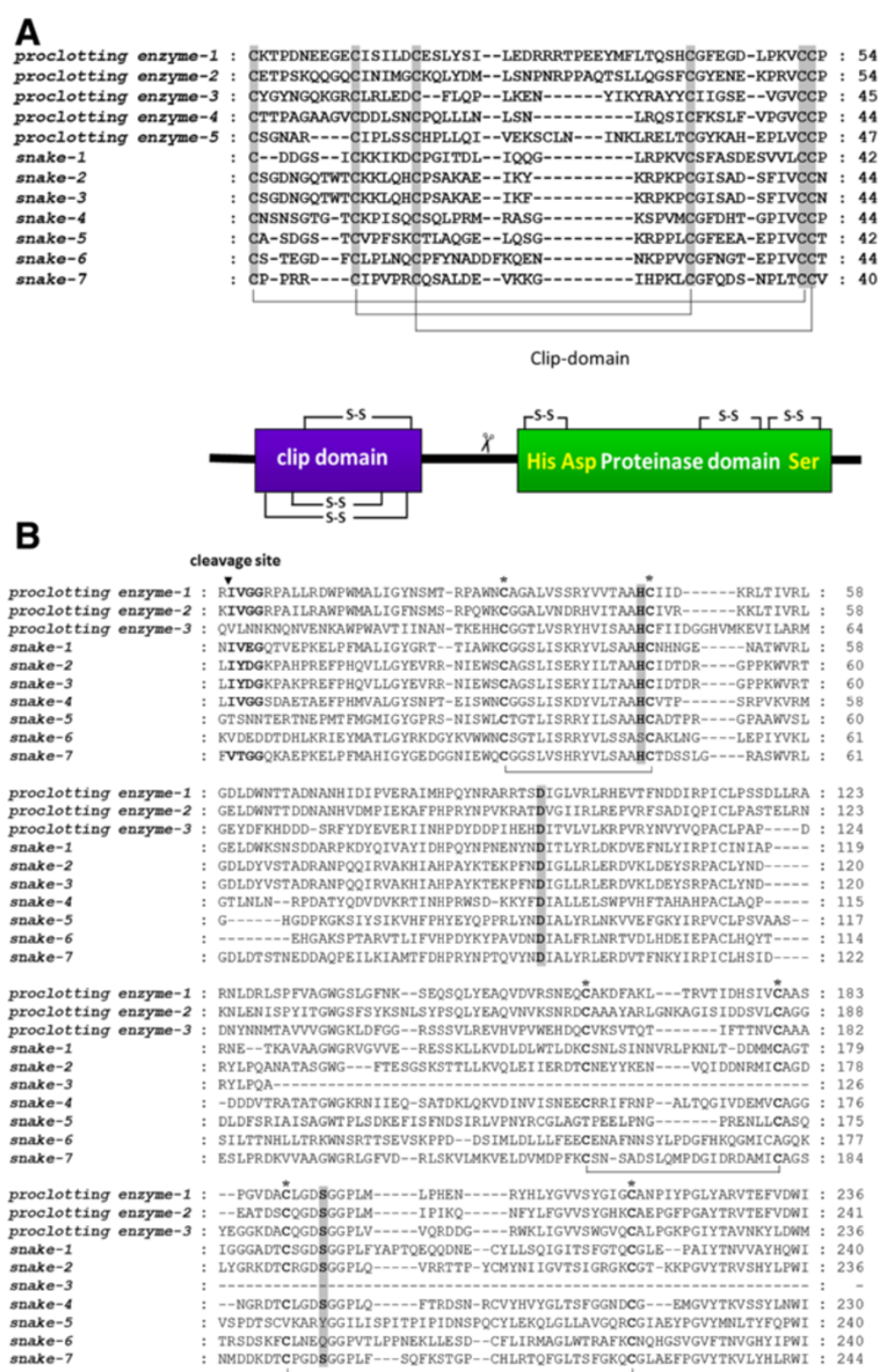

Figure 8 (A) Alignments of the $\mathbf{N}$-terminal clip-domains of $\mathbf{N}$. lugens CLIPs. (B) The C-terminal serine protease domains of N. lugens CLIPS. The CLUSTALW program was used for alignments. The gray shades indicate the conserved cysteine residues and active triad (His, Asp and Ser). The predicted disulfide linkages between conserved cysteines are shown by lines. The possible proteolytic cleavage site is indicated with an arrowhead $[42,45]$.

7 genes (GenBank accession no. KC355223-KC355225) include 6-8 exons had the same transcription orientations. These CLIP genes were flanked by the additional three non-clip domain serine protease genes (Figure 7C). The typical clip domain was highly conserved in the deduced $N$. lugens CLIPs, which includes six cysteine residues that possibly form three putative disulfide linkages (Figure $8 \mathrm{~B}$ ). In addition, three amino acid residues (His, Asp and Ser), which are essential for the catalytic activity of serine proteases, were present in the C- terminal domain of CLIPs, except for Nlsnake5 and Nlsnake6. Three disulfide linkages are probably formed among six cysteine residues in the serine protease domain (Figure 8B). CLIPs are typically synthesized as inactive zymogens and are required for activation by a specific proteolytic cleavage, which forms a regulatory light chain and a catalytic heavy chain [44]. A possible cleavage site was found in the junction region of the $\mathrm{N}$ and C-terminal domains of the $N$. lugens CLIPs including Nlproclotting enzyme 1-2, Nlsnake1-4 and Nlsnake7 
genes, thus implying that a proteolytic digestion occurs between the clip and serine protease domains in these CLIPS (Figure 8B).

Serine protease inhibitors (serpins) present in insect hemolymph regulate the proPO activation cascade, where they function as the negative regulators to avoid excessive activation of the cascade [46]. In Drosophila, a well-known serpin, spn27A prevented extensive melanization by inhibiting the proPO activating protease [47]. In Manduca sexta, at least five serpins (serpin $1 \mathrm{~J}$ and 36) blocked the proPO activation in the cascade [48-50]. In this study, nine serpin genes were identified in the $N$. lugens genome. These genes distribute in different scaffolds and show high sequence similarities with insect serpins, especially the hemimetabolous species (Table 3 ). We designated them as Nlserpin1-9. A search of the $N$. lugens transcriptome determined that six genes (Nlserpin1-6) consisted of a predicted signal peptide sequence and a core serpin domain, suggesting that they are secreted proteins (Figure 9). Their deduced amino acids shared 53\%-73\% similarities with insect serpins (Table 3). The putative protein product of Nlserpin 7 gene shared a 57\% similarity with $A$. pisum plasminogen activator inhibitor 1 , a secreted type of serpin. Despite the significant identity, Nlserpin7 lacked the putative signal peptide sequence. Its sequence featured two internal repeats at the $\mathrm{N}$-terminus, except for a major serpin domain. The structure prediction implies that $N$. lugens serpin7 is likely to be an intracellular protein.

We analyzed the expression pattern of six CLIP genes in the salivary gland, fat body, gut, and carcass (Figure $3 \mathrm{C}$ ). Their transcripts were detected at very low levels in the gut, suggesting that they probably do not function in digestion. Two genes, including proclotting enzyme 2 and

\section{N. Lugens serine protease inhibitors}

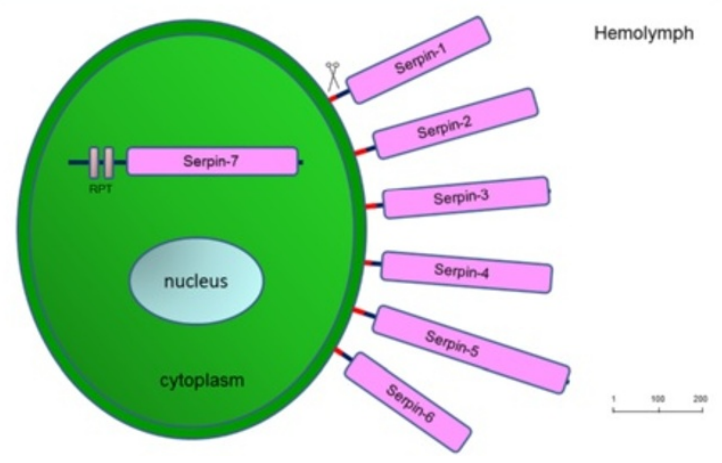

Figure 9 The structure prediction and cellular distribution of the deduced $\boldsymbol{N}$. lugens serpins. Red bars and rectangles indicate the putative signal peptide and the core serpin domains, respectively. RPT indicates two $\mathrm{N}$-terminal internal repeats of serpin7, which may be retained in the cytoplasm. The size bar indicates the amino acid residues of the deduced serpins. snake 2, exhibited the highest expression levels in the carcass among the analyzed tissues, implying that they have potential functions in the epidermis. The other CLIPS showed the high transcript levels in the salivary gland, suggesting that these genes might play the important roles in this tissue.

\section{Immune responsive effector genes}

Most microbial pathogens are able to induce the expression of insect effector genes, which are generally synthesized in some specific tissues, such as fat body and hemocytes, before being released into the hemolymph where they directly attack the invaders or are involved in the proPO cascade-dependent malanization responses. The antibacterial peptides are a group of immuneresponsive effectors that are regulated by the Toll and Imd signaling pathways and play important roles in the humoral defense systems of insects [51]. A variety of antibacterial peptide genes were isolated and characterized from many insect species. In this study, defensins are the available antibacterial peptide genes identified in the $N$. lugens genome. Several other effector genes, including reeler, lysozyme, and NOS, are present in the $N$. lugens genome.

Reeler is an immune-responsive gene which mediates the nodulation response upon bacterial infection [52]. Reeler features a reeler domain, which was initially identified in the mouse reelin protein, a secreted glycoprotein which plays a pivotal role in the development of the central nervous system in mammals [53]. At present, reeler genes are well characterized only in lepidopteran insects including Hyphantria cunea [54], Manduca sexta [53], Samia cynthia ricini [55], Lonomia obliqua [56], Antheraea mylitta [52] and B. mori [57]. In this study, the $N$. lugens genome and transcriptome revealed one reeler gene (GenBank accession no. KC355218), which encodes 163 amino acid residues consisting of a putative signal peptide and a characteristic reeler domain. The predicted molecular weight of mature Reeler protein is $15.3 \mathrm{kDa}$. The reeler domain spans nearly the entire coding regions of $N$. lugens reeler (Figure 10A). The $N$. lugens reeler gene is $2.1 \mathrm{~kb}$ long and contains three exons. A comparison of the gene structure among several genome-available insect species revealed that the significant difference of the reeler gene sizes is that it varies from $0.96 \mathrm{~kb}$ to $8.0 \mathrm{~kb}$, although these genes include no more than four exons. The deduced proteins showed that these reelers are composed of a signal peptide sequence with 17-26 amino acid residues and a reeler domain of 124-137 amino acid residues (Figure 10B). The phylogenetic tree shows that lepidopteran reelers form an independent cluster, while the $N$. lugens reeler distantly locates in another independent cluster and is closely related 


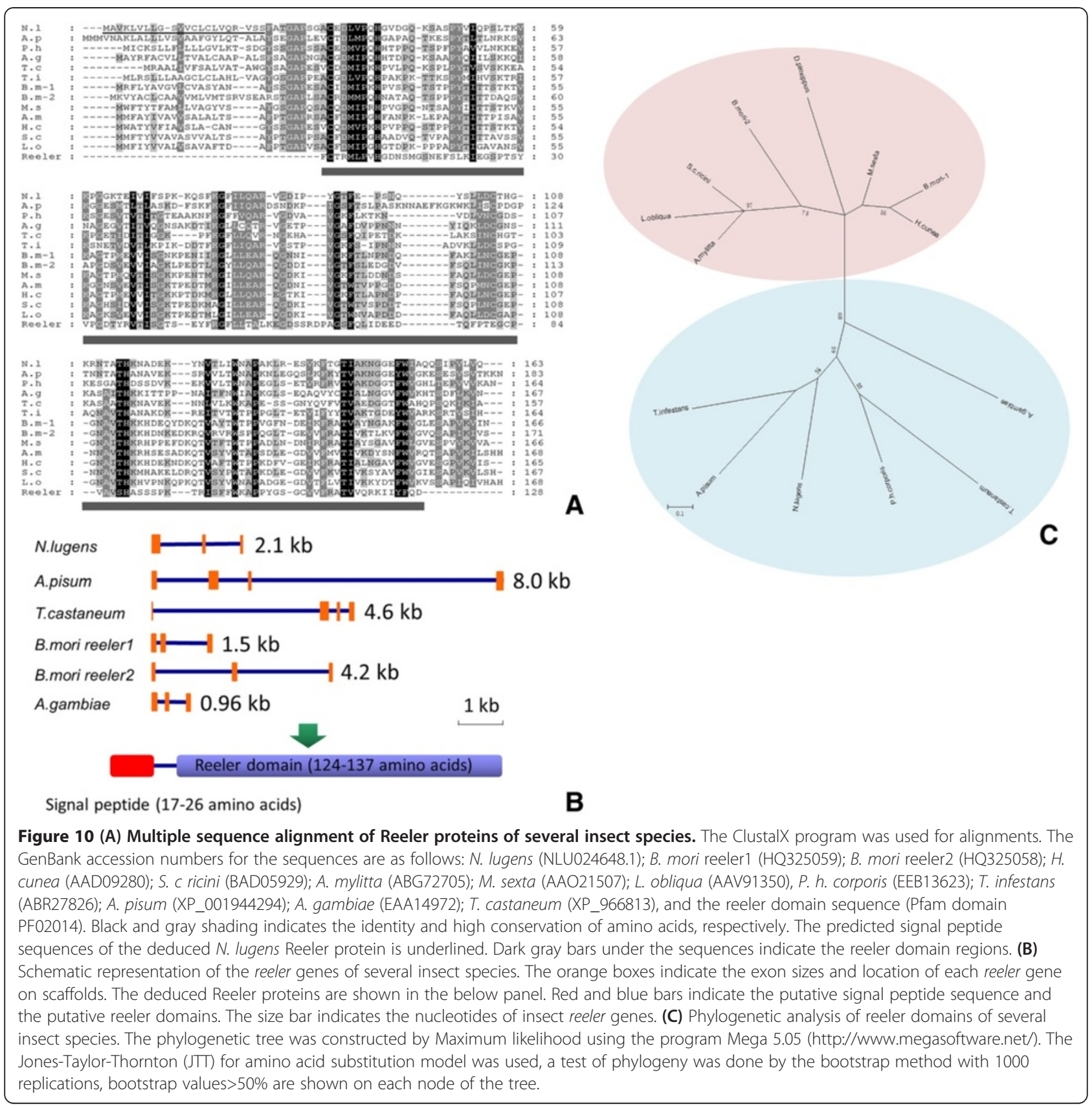

to the homologues of two hemimetabolous species, namely $T$. infestans and $A$. pisum (Figure 10C).

We identified two defensin genes in the $N$. lugens genome. As an antibacterial peptide, defensin plays an important role in insect defense systems. These two defensin genes are located at the same scaffold. One defensin gene (GenBank accession no. KC355196) contains two exons flanked by the $5^{\prime}$ and $3^{\prime}$ UTRs; the other (GenBank accession no. KC355195) also contains two exons but has no 5 and $3^{\prime}$ UTR sequences (Figure 11). Accordingly, the $N$. lugens transcriptome revealed two defensin transcripts. Their deduced peptides include 104 amino acid residues which share $86.5 \%$ identities. The two $N$. lugens defensins showed $74 \%$ sequence similarities with $T$. infestans defensin $A$ and Rhodnius prolixus defensin $B$, respectively. We designated them as Nldefensin $A$ and Nldefensin $B$ (Table 4).

Lysozymes constitute a large and diverse family of hydrolytic enzymes. They catalyze the hydrolysis of the $\beta$-1, 4-glycosidic linkage between $N$-acetyl muramic acid and $N$-acetylglucosamine of PGN. Three major distinct lysozymes, namely the c-type (chicken type), g-type 
(goose type) and i-type (invertebrates), have been identified in animals [58]. The most ubiquitous of these enzymes is the c-type lysozyme, which is widely distributed in vertebrates and invertebrates. G-type lysozymes do not seem to occur in invertebrates other than some bivalve mollusk scallops $[59,60]$ and the tunicates $[61,62]$. I-type lysozymes are restricted to invertebrates. All available insect genomes contain i-type lysozymes, suggesting these enzymes are widespread in insects (www.ncbi.nlm. nih.gov/2012.July). Despite the differences in the amino acid sequences and the biochemical properties, the functions of lysozymes were widely recognized for their contribution to antibacterial defense. In addition, some c- and i-type lysozymes function as digestive enzymes in insects, for example in Anopheles gambiae [63,64]. In this study, we identified one c-type lysozyme gene from the $N$. lugens genome and transcriptome (Table 4). The putative molecular weight of a mature $N$. lugens c-type lysozyme is $14.68 \mathrm{kDa}$. A signal peptide sequence is predicted at its $\mathrm{N}$-terminus. The deduced $N$. lugens c-type lysozyme showed significant sequence similarity with the enzymes from several insect species, including dipteran, lepidopteran, hemipteran, and anoplura insects. Eight cysteine residues, which possibly form intramolecular disulfide bridges and two potential catalytic sites, namely glutamic acid and aspartic acid residues, are highly conserved in these enzymes. This may be important for the structural stability, as well as for the enzymatic activity of lysozymes (Figure 12A). Thus far, the presence of multiple i-type lysozymes has only been reported in a few mollusk species [6,65-68], as well as the mosquito A. gambiae [64] and the medial leech Hirudo medicinalis [69]. In this study, seven i-type lysozyme genes were identified in $N$. lugens and designated as Nli-lysozyme1-7. Their deduced sequences showed high similarities with the homologues from Periplaneta americana (Neoptera), Nasonia vitripennis, Apis mellifera, Acyrthosiphon pisum and Culex quinquefasciatus (Figure 12B). The putative signal peptides were present in the deduced amino acid sequences of $N$. lugens i-type lysozyme-2, 3, 5, and 7. The

Table 4 The gene prediction of $N$. lugens immune responsive effectors

\begin{tabular}{|c|c|c|c|c|c|c|c|c|c|c|}
\hline Predicted gene & GenBank ID & Locus & Size (aa) & Exon & Orientation & UTR & Best match & Similarity & Mw & pl \\
\hline reeler & KC355218 & scaffold666 & 163 & 3 & + & no & T. infestans & $60 \%$ & 15.31 & 9.28 \\
\hline defensin $B$ & KC355196 & scaffold229 & 104 & 2 & + & have & R.prolixus & $74 \%$ & 8.35 & 8.31 \\
\hline defensin A & KC355195 & scaffold229 & 104 & 2 & + & no & T. infestans & $74 \%$ & 8.36 & 6.06 \\
\hline c-type lysozyme & KC355194 & scaffold427 & 154 & 2 & - & no & P.h. corporis & $68 \%$ & 14.68 & 6.64 \\
\hline i-type lysozymel & KC355204 & scaffold515 & partial & 3 & + & no & P. americana & $58 \%$ & & \\
\hline i-type lysozyme2 & KC355205 & scaffold2772 & 158 & 3 & - & no & A. pisum & $75 \%$ & 15.22 & 5.09 \\
\hline i-type lysozyme3 & KC355206 & scaffold374 & 163 & 6 & - & no & P.americana & $76 \%$ & 15.40 & 5.06 \\
\hline i-type lysozyme4 & KC355207 & scaffold6850 & partial & 3 & - & no & P.americana & $77 \%$ & & \\
\hline i-type lysozyme5 & KC355208 & scaffold186 & 166 & 3 & - & no & P.americana & $55 \%$ & 15.89 & 5.29 \\
\hline i-type lysozyme6 & KC355209 & scaffold186 & partial & 3 & + & no & P.americana & $62 \%$ & & \\
\hline i-type lysozyme7 & KC355210 & scaffold83 & 176 & 4 & + & have & D. plexippus & $48 \%$ & 17.69 & 7.88 \\
\hline
\end{tabular}

The genomic organization of exons and introns of the immune responsive genes was predicted based on the mRNA-genome alignments at the NCBI spideyweb (http://www.ncbi.nlm.nih.gov/spidey/spideyweb.cgi). Molecular weight (Mw) and isoelectric point (pl) were analyzed using Compute pl/MW tool (http://web. expasy.org/compute_pi/). T. infestans, Triatoma infestans; R. prolixus, Rhodnius prolixus; P. $h$. corporis, Pediculus humanus corporis; P. americana, Periplaneta Americana; A. pisum, Acyrthosiphon pisum; D.plexippus, Danaus plexippus. 
(See figure on previous page.)

Figure 12 Multiple sequence alignments of lysozymes of several insect species. (A) c-type lysozyme aligments; (B) i-type lysozyme aligments. The ClustalX program was used for alignments. The GenBank accession numbers for the sequences are as follows: Pediculus humanus corporis lysozyme P precursor (EEB19248); Bombyx mori lysozyme precursor (AAB40947); Manduca sexta lysozyme (AAB31190); Aedes aegypti lysozyme P (EAT44944), Triatoma infestans lysozyme (AAP83129), Culex quinquefasciatus lysozyme (EDS45638), Drosophila melanogaster lysozyme P (AAF47452), Periplaneta americana i-type lysozyme (AFI81521), C. quinquefasciatus lysozyme i-1 (EDS32730), Acyrthosiphon pisum lysozyme 1-like (XP_001949318), Nasonia vitripennis lysozyme 3-like (XP_001600829) and Apis mellifera lysozyme isoform 1 (XP_393161). The predicted signal peptide sequences of lysozymes are underlined. Gray shading indicates the conserved cysteine residues and the putative catalytic sites of the enzymes. (C) Phylogenetic analysis of insect c- and i-type lysozymes. The phylogenetic tree was constructed by Maximum likelihood, using the program Mega 5.05 (http://www.megasoftware.net/). The Jones-Taylor-Thornton (JTT) for amino acid substitution model was used, the test of phylogeny was done by the bootstrap method with 1000 replications, bootstrap values $>50 \%$ are shown on each node of the tree. N.I, N. Iugens; D.m, Drosophila melanogaster; A.p. Acyrthosiphon pisum; A.m. Apis mellifera; B.m, Bombyx mori; M. s, M. sexta; C. q, C. quinquefasciatus; T. i, T. infestans; A. a, A. aegypti; P. h. C, P. h. corporis; P. a, P. Americana and N. v, N. vitripennis.

protein products of $N$. lugens i-type lysozyme-2, 3 and 5 were predicted to have calculated isoelectric points (pI) of around 5.0, and molecular weights of 15-16 kDa; while $N$. lugens $i$-type lysozyme-7 has a molecular weight $17.69 \mathrm{kDa}$ heavier than the others, and is seemingly a basic enzyme with the $\mathrm{pI}$ of 7.88. $N$. lugens i-type lysozyme-1, 4, and 6 did not show the signal peptide sequences, due to their incomplete sequences. Twelve cysteine residues were highly conserved in these deduced i-type lysozymes with the exception of the $N$. lugens i-type lysozyme 7, which contained eight cysteine residues. Reduction of disulfide bridges decreases the antibacterial activity of lysozymes [70]. The catalytic sites, glutamic acid and aspartic acid residues are not conserved in these enzymes. Whether these i-type lysozymes are inactive, or whether the glutamic acid and aspartic acid residues are necessary for their enzymatic activity, is not clear. Zavalova et al. [71] proposed evidence for a non-enzymatic antibacterial mode of action of lysozyme in invertebrates, as high antimicrobial activity was detected in a heat-treated lysozyme which lacked glycosidase activity towards both Micrococcus luteus and E. coli. Similarly, Cong et al. [72] have very recently indicated that the sea cucumber i-type lysozyme has both enzymatic and non-enzymatic antibacterial action. The precise function of $N$. lugens lysozymes remains a mystery. We compared the phylogenetic relationship of these distinct lysozyme genes with several insect species. $C$ and $i$-type lysozymes form two independent clusters, respectively (Figure 12C). In the c-type lysozyme cluster, the $N$. lugens gene is closely related to the homologue of Pediculus humanus corporis, a hemimetabolous species. In the i-type lysozyme group, while $N$. lugens lysozyme-1, 5 , and 6 are clustered together and more closely related to $N$. lugens lysozyme-3 than lysozyme-2, the $N$. lugens lysozyme-7 is distantly located from the other $N$. lugens lysozyme genes.

$N$. lugens defensin $A$ and defensin $B$ gene expressions were strongly induced by both $E$. coli $\mathrm{k} 12$ and $B$. subtilis from 6-12 h p.i, while reeler gene expression was significantly up-regulated by the E. coli $\mathrm{k} 12$ challenge, but seemed not to be induced by B. subtilis (Figure 2). We also analyzed the $N$. lugens lysozyme gene expression upon bacterial infection (Figure 2). C-type lysozyme gene expression was strongly induced by E. coli $\mathrm{k} 12$ from $12 \mathrm{~h}$ p.i and decreased at $24 \mathrm{~h}$ p.i, whereas its expression was notably decreased by $B$. subtilis injection at $6 \mathrm{~h}$ p.i, before it gradually increased from $12 \mathrm{~h}$ p.i and recovered to the constitutive level at $24 \mathrm{~h}$ p.i. The $i$-type lysozyme- 1 gene exhibited a different expression pattern. E. coli k12 and $B$. subtilis did not rapidly increase $i$-type lysozyme-1 gene expression levels upon infection, but slowly upregulated its expression levels at $24 \mathrm{~h}$ p.i. Several other $N$. lugens $i$-type lysozyme genes also appeared to cause a similar inducible expression pattern (data not shown). The results suggest that these $N$. lugens effector gene expressions are responsive to foreign pathogen infection.

$N$. lugens defensin genes showed very high expression levels in salivary glands of the 5th instar nymphs. Their transcripts were also detected at relatively high levels in the fat body followed by the gut, although extremely low levels were found in the carcass (Figure 3D). Reeler gene expression showed different tissue specificity; the transcripts of which were detected at much higher levels in the salivary gland and carcass than in the fat body, although the lowest levels were found in the gut suggesting this reeler gene may not contribute to the gut immunity. The c-type lysozyme gene displayed an exclusive expression in the salivary gland. I-type lysozyme genes showed similar expression patterns, with their transcripts exhibiting their highest levels in the salivary gland followed by the fat body, while the lowest levels were found in the gut. The fat body is thought by many to represent important immune-related tissues in insects. However, in this study, our findings indicate that the salivary gland is more likely to be the most important tissue with regards to immune defense responses in N. lugens.

\section{Development and sex-specific expression}

In our previous study, we obtained $N$. lugens development and sex-specific expression profile data, including eggs, 2nd instar nymphs, 5th instar nymphs, female and 


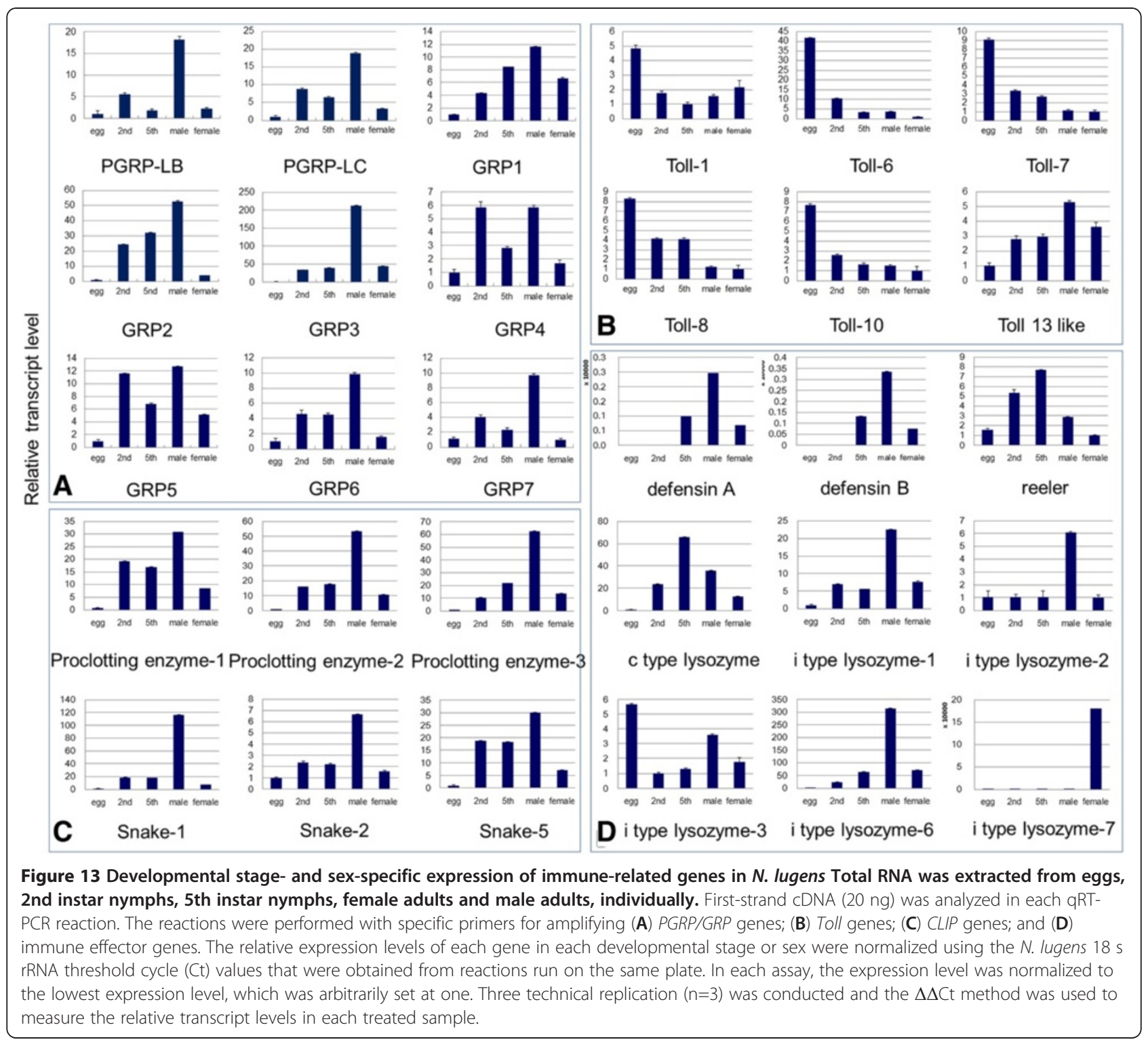

male adults [6]. In this study, we focused on some immune-related genes and analyzed their expressions in the different developmental stages and sexes. $N$. lugens $P G R P$ and GRP genes showed much higher expression levels in male adults than in female adults (Figure 13A). These genes also had relatively high expression levels in 2nd instar and/or 5th instar nymphs, although extremely low levels were found in eggs. Similarly, $N$. lugens CLIP genes also had significantly high expression levels in male adults when compared to the female adults (Figure 13C). Their transcripts were detected in nymphs, but were barely detectable in eggs. Several immune responsive effector genes exhibited different expression patterns. Two defensin genes possessed the identical expression pattern; while their transcripts were detected at the highest levels in male adults followed by the 5th instar nymphs, but were hardly detected in the eggs or the 2nd instar nymphs (Figure 13D). The reeler gene showed a distinct expression pattern, with the maximum transcript levels being detected in the 5th instar nymphs followed by the 2nd instar nymphs. However, low transcript levels were observed in eggs and adults. The c-type lysozyme gene showed a significantly high expression level in the 5th instar nymphs, while the i-type lysozyme-3 gene had the highest expression level in eggs. Several other i-type lysozyme genes (1, 2, and 6) displayed a similar expression pattern, and their transcripts were detected at the highest levels in male adults. The i-type lysozyme-7 gene had a completely different expression pattern, with transcripts exclusively detectable in female adults. Toll genes including Toll-1, 6, 7, 8 and 10 showed the highest expression levels in eggs; in 
Table $\mathbf{5}$ Immune-related genes in several insect species

\begin{tabular}{|c|c|c|c|c|c|c|c|}
\hline Functional classidication & Gene & N.lugens & A. pisum & D. melanogaster & A. gambiae & A. mellifera & B. mori \\
\hline \multirow[t]{10}{*}{ Pattern recognition molecules } & PGRp & 2 & 0 & 13 & 7 & 4 & 12 \\
\hline & $\beta G R P / G N B P$ & 7 & 1 & 3 & 7 & 2 & 4 \\
\hline & C-type lectin & 9 & 10 & 34 & 25 & 10 & 21 \\
\hline & hemocytin & 1 & 1 & 1 & 0 & 1 & 2 \\
\hline & hemolin & 0 & 0 & 0 & 0 & 0 & 1 \\
\hline & galectin & 2 & 1 & 6 & 8 & 2 & 4 \\
\hline & dscam & 9 & 1 & 1 & 1 & 1 & 1 \\
\hline & Draper & 1 & 1 & 1 & 1 & 1 & 1 \\
\hline & Eater & 1 & 0 & 1 & 1 & 0 & 0 \\
\hline & toll & 6 & 5 & 9 & 10 & 5 & 14 \\
\hline \multirow[t]{8}{*}{ Toll pathway } & cactus & 1 & 1 & 1 & 1 & 3 & 1 \\
\hline & myD88 & 2 & 0 & 1 & 1 & 1 & 1 \\
\hline & spatzle & 8 & 4 & 6 & 6 & 2 & 3 \\
\hline & pelle & 1 & 1 & 1 & 1 & 1 & 1 \\
\hline & tube & 1 & 1 & 1 & 1 & 1 & 1 \\
\hline & Dorsal/Dif & 1 & 1 & 2 & 1 & 2 & 1 \\
\hline & tollip & 1 & 1 & 1 & 2 & 1 & 2 \\
\hline & dred & 1 & 0 & 1 & 1 & 1 & 1 \\
\hline \multirow[t]{10}{*}{ Imd pathway } & imd & 1 & 0 & 1 & 1 & 1 & 1 \\
\hline & relish & 1 & 0 & 1 & 1 & 2 & 1 \\
\hline & caspar & 3 & 2 & 2 & 1 & 2 & 1 \\
\hline & IKK & 2 & 1 & 2 & 2 & 2 & 2 \\
\hline & Tak1 & 1 & 0 & 2 & 1 & 1 & 1 \\
\hline & IAP2 & 1 & 1 & 1 & 1 & 1 & 1 \\
\hline & Ubc13 & 1 & 1 & 1 & 1 & 1 & 1 \\
\hline & TRAF & 2 & 2 & 2 & 1 & 2 & 1 \\
\hline & Tab2 & 1 & 1 & 1 & 1 & 1 & 1 \\
\hline & Hopscoch & 1 & 1 & 1 & 1 & 1 & 1 \\
\hline \multirow[t]{5}{*}{ JAK-STAT pathway } & PIAS & 1 & 12 & 1 & 1 & 2 & 1 \\
\hline & SOCS & 5 & 5 & 3 & 1 & 4 & 3 \\
\hline & STAT & 1 & 2 & 1 & 2 & 1 & 1 \\
\hline & Domeless & 1 & 1 & 1 & 1 & 1 & 1 \\
\hline & Clip-domain protease & 12 & 6 & 37 & 41 & 18 & 15 \\
\hline \multirow[t]{2}{*}{ proPO cascade } & Serpin protease inhibitor & 9 & 14 & 30 & 17 & 5 & 26 \\
\hline & Lysozyme & 8 & 3 & 17 & 8 & 3 & 4 \\
\hline \multirow[t]{9}{*}{ Immune-responsive effector } & Reeler & 1 & 2 & 2 & 2 & 1 & 3 \\
\hline & Defensin & 2 & 0 & 1 & 4 & 2 & 1 \\
\hline & Attacin & 0 & 0 & 4 & 1 & 0 & 2 \\
\hline & Cecropin & 0 & 0 & 4 & 4 & 0 & 13 \\
\hline & Diptericin & 0 & 0 & 2 & 0 & 0 & 0 \\
\hline & Drosocin & 0 & 0 & 1 & 0 & 0 & 0 \\
\hline & Drosomycin & 0 & 0 & 7 & 0 & 0 & 0 \\
\hline & Gloverin & 0 & 0 & 0 & 0 & 0 & 4 \\
\hline & Lebocin & 0 & 0 & 0 & 0 & 0 & 1 \\
\hline
\end{tabular}


Table 5 Immune-related genes in several insect species (Continued)

\begin{tabular}{llllll}
\hline Metchnikowin & 0 & 0 & 1 & 0 & 0 \\
Moricin & 0 & 0 & 0 & 0 & 0 \\
Nuecin & 0 & 0 & 0 & 0 & 0 \\
NOS & 1 & 1 & 1 & 1 & 1 \\
\hline
\end{tabular}

The number of immune-related genes in insect species was obtained from NCBI databases (http://www.ncbi.nlm.nih.gov/2012.July) coupled with the available genome databases of the insect species: A. pisum (www.inra.fr/aphidbase/); B. mori (ftp://silkdb.org/pub/release_2.0/); D. melanogaster ftp.flybase.org/genomes/ Drosophila_melanogaster/dmel_r5.27_FB2010_04/); A. gambiae (ftp.vectorbase.org/public_data/organism_data/agambiae/Geneset/) and A. mellifera (hymenopteragenome.org/drupal/sites/hymenopteragenome.org.beebase/files/data/).

contrast, the Toll-13 like gene had the lowest expression level in eggs (Figure 13B). The fact that the significantly high expressions appeared in eggs, that is Toll genes and an $i$-type lysozyme gene, suggests that they may function not only in immunity but also in embryogenesis and development. It is interesting that the majority of $N$. lugens immune-related genes had a common high expression pattern in male adults but low levels in female adults. In $N$. lugens, female adults possess many more abundant microbial symbionts than do male adults. Our findings indicate a possible immune strategy whereby female adults reduce their immune capabilities to maintain the microbial symbionts in order to meet the requirements of nutrition, development, and reproduction.

\section{A comparison of immune-related genes among insect species}

In this study, the genome- and transcriptome-wide analysis revealed an intact innate immune network presenting in $N$. lugens. This network included the abundant pattern recognition proteins, signal transduction components involved in Toll, Imd and JAK/STAT pathways, modulation molecules in proPO activating cascade and immune responsive effectors. Comparative genome data showed that the key pattern recognition, signal transduction and modulation molecules are common in several insect species; however, the components of antibacterial peptides are different (Table 5). Antibacterial peptides play important roles in the humoral defense systems of insects. The well-known attacin, cecropin, gloverin, lebocin and moricin in lepidopteran insects and diptericin, drosocin, drosomycin, metchnikowin and nuecin in dipteran insects, are absent in the $N$. lugens genome. Defensins are the unique antibacterial peptide genes available in the $N$. lugens genome. A lack of most antibacterial peptides may be an effective strategy by which to maintain symbiotic systems in N. lugens.

A genome-wide comparison of two hemimetabolous species, $N$. lugens and $A$. pisum, revealed that the major signal transducers in the Imd pathway including IMD, Dredd and Relish are lacking in the A. pisum genome [73], while the corresponding components are conserved in the $N$. lugens genome. As pattern recognition proteins, PGRPs are required to trigger the signal transduction via the Toll and Imd pathways in insects. Two PGRP genes were identified in the N. lugens genome. In contrast, the $A$. pisum genome lacked the PGRP sequence information. Eater is another pattern recognition receptor for binding a broad range of bacterial pathogens and mediating phagocytosis in Drosophila cellular immune responses [74]. An eater gene is identified in the $N$. lugens genome, but not detected in the A. pisum genome. In addition, the key signal transducer myd88 in Toll pathway and antibacterial peptide genes were not found in the $A$. pisum genome. The genomic comparison between the two hemimetabolous insect species showed that $N$. lugens seemed to own a more comprehensive and complex innate immune system than $A$. pisum.

\section{Conclusions}

A number of immune-related genes that are emerging in $N$. lugens constitute an integrated picture of the immune network, which provides the valuable clues for a better understanding of the immunological process under physiological and pathogenic conditions in this hemimetabolous insect. This immune system may primarily defend not only foreign pathogens, but is also designed to tolerate non-pathogenic microorganisms, such as microbial symbionts. In addition, the immune system may play important roles in the development, reproduction, and virus transmission of $N$. lugens. The expression specificity and biological function of additional genes identified in this study will need to be further elucidated. This would be useful for clarifying the detailed physiological and immunological mechanisms in $N$. lugens and could provide potential targets for this pest management in the future.

\section{Methods}

Insects

The $N$. lugens strain was originally collected from a rice field located in the Huajiachi Campus of Zhejiang University, Hangzhou, China. The insects used in this experiment were the offspring of a single female and were reared at $27 \pm 0.5^{\circ} \mathrm{C}$ with $70 \%$ humidity on rice seedlings (Xiushui 128) under a 16:8 h light:dark photoperiod. $N$. lugens eggs, 2nd instar nymphs, 5th instar 
nymphs, female and male adults were used for analyzing the development and sex-specific gene expressions.

\section{Immunization and collection of tissues}

$N$. lugens 5th instar nymphs were anesthetized with carbon dioxide for $5-10 \mathrm{~s}$ at $\mathrm{PCO}_{2}=5 \mathrm{mPa}$. The nymphs were immunized by microinjection of heat-killed $E$. coli K12 (gram-negative bacteria)or Bacillus subtilis (grampositive bacteria) $\left(5 \times 10^{7}\right.$ cells suspended in $10 \mathrm{ml}$ of PBS) using the FemtoJet Microinjection System (Eppendorf, North America). Nymphs were collected at 6, 12 and $24 \mathrm{~h}$ after the microinjection in order to analyze the bacteria-induced gene expressions.

For tissue extraction, the 5th instar nymphs were dissected under a Leica S8AP0 stereomicroscope. The tissues including fat body, gut, salivary gland and the remaining carcass were isolated and quickly washed in a diethylpyrocarbonate (DEPC)-treated PBS solution (137 mM NaCl, $2.68 \mathrm{mM} \mathrm{KCl}, 8.1 \mathrm{mM} \mathrm{Na} \mathrm{HPO}_{4}$, $\left.1.47 \mathrm{mM} \mathrm{KH}_{2} \mathrm{PO}_{4}, \mathrm{pH} 7.4\right)$. As the quantity of an individual nymph is extremely low, each tissue from 100 nymphs was pooled into one sample individually and was immediately frozen at $-80^{\circ} \mathrm{C}$.

\section{Identification of Immune-related genes from $N$. lugens genome and transcriptomes}

The available immune-related gene sequences from other insect species were used as references to screen the $N$. lugens genomic (unpublished) and transcriptomic databases [6,7]. The candidates of $N$. lugens immune-related genes were confirmed by searching the BLASTX algorithm against the non-redundant (nr) NCBI nucleotide database using a cut-off E-value of $10^{-5}$. The genomic organization of exons and introns of the immune-related genes was predicted based on the mRNA-genome alignments at the NCBI spideyweb (http://www.ncbi. nlm.nih.gov/spidey/spideyweb.cgi). The deduced protein domains and signal peptides were determined by using Pfam (http://www.sanger.ac.uk/Software/Pfam/), SMART (http://smart.embl.de/) and InterProScan (http:// www.ebi.ac.uk/Tools/pfa/iprscan/). Molecular weight and isoelectric point were analyzed via Compute $\mathrm{pI} / \mathrm{MW}$ tool (http://web.expasy.org/compute_pi/). Immune-related genes in the genomes of the several other insect species were investigated for Acyrthosiphon pisum (www.inra.fr/ aphidbase/), Drosophila melanogaster (ftp.flybase.org/genomes/Drosophila_melanogaster/dmel_r5.27_FB2010_ 04/), Apis mellifera (hymenopteragenome.org/drupal/ sites/hymenopteragenome.org.beebase/files/data/), Anopheles gambiae (ftp.vectorbase.org/public_data/organism_ data/aaegypti/Geneset/) and Bombyx mori (ftp://silkdb.org/ pub/release_2.0/).

\section{Phylogenetic analysis}

The functional domains of the deduced $N$. lugens immune-related proteins were aligned with the bestmatched orthologs of other insect species using Clustal $\mathrm{X}$ program [75]. The phylogenic trees were constructed by Maximum likelihood using the program Mega 5.05 (http://www.megasoftware.net/). Orthologous relationships were determined using the bootstrap analysis with values of 1000 trials.

\section{Quantitative real-time PCR (qRT-PCR) analysis}

Total RNA was isolated from $N$. lugens specimens using the SV Total RNA Isolation System (Promega). The concentration of RNA was adjusted with DEPC-treated $\mathrm{H}_{2} \mathrm{O}$ to $1 \mu \mathrm{g} / \mu \mathrm{l}$, and $1 \mu \mathrm{g}$ of RNA was reverse-transcribed in a $10 \mu \mathrm{l}$ reaction using the ReverTra Ace ${ }^{\circledR}$ qPCR RT Master Mix with gDNA Remover Kit (ToYoBo). qRTPCR was performed on an BIO-RAD CFX96 ${ }^{\mathrm{TM}}$ Real-Time System (Bio-Rad) using the $\mathrm{iQ}^{\mathrm{Tm}}$ SYBR Green ${ }^{\circledR}$ Supermix Kit (Bio-Rad), according to the manufacturers' instructions. The first-strand cDNA $(2 \mu \mathrm{l})$ and the no-template control (NTC, $2 \mu \mathrm{l}$ ) were used as templates for three technical replication assays in each $20 \mu$ l reaction mixture under the following conditions: denaturation at $95^{\circ} \mathrm{C}$ for $2 \mathrm{~min}$, followed by 40 cycles of $95^{\circ} \mathrm{C}$ for $15 \mathrm{~s}$ and $60^{\circ} \mathrm{C}$ for 30 s. Fluorescence of PCR products was detected by adding a heat-dissociation protocol (temperature range, 65 to $95^{\circ} \mathrm{C}$ ) during the last step of each cycle. Following amplification, melting curves were constructed and data analysis was performed on Bio-Rad CFX Manager 2.1 software. Specific primers are shown in Additional file 1: Table S1. As an internal control, the expression of $N$. lugens 18 s rRNA gene (GenBank accession no. JN662398) was analyzed using the following primers: $5^{\prime}$-CGCTA CTACCGATTGAA-3' (sense primer) and 5'-GGAAA CCTTGTTACGACTT-3' (antisense primer). The specificity of the primers was confirmed using NCBI BLAST algorithms (http://www.ncbi.nlm.nih.gov/). The results were standardized to the expression level of $N$. lugens $18 \mathrm{~s}$ rRNA. An NTC sample was run to detect any contamination and to determine the degree of dimer formation. The $\Delta \Delta \mathrm{C}_{\mathrm{t}}$ method was used to analyze the relative differences in the transcript levels.

\section{Additional file}

Additional file 1: Table S1. Primers used in real-time qPCR for immune-related gene specific expressions.

\section{Abbreviations}

PGN: Peptidoglycan; PGRP: Peptidoglycan recognition protein; $\beta$ GRP: $\beta$ glucan recognition protein; GNBP: Gram-negative binding protein; CLIP: Clipdomain serine proteases; bp: Base pair; CDS: Coding sequence; RACE: Rapid amplification of cDNA ends; UTR: Untranslated region; PO: Phenoloxidase; proPO: Prophenoloxidase; YLS: Yeast-like symbiont; Imd: Immunodeficiency; 
JAK-STAT: Janus kinase/signal transducers and activators of transcription; DEPC: Diethylpyrocarbonate; NTC: No-template control; LRR: Leucine-rich repeats; TIR: Toll-interleukin homolog domain; qRT-PCR: Quantitative realtime PCR; Ig: Immunoglobulin; Dscam: Down syndrome cell adhesion molecule.

\section{Competing interests}

The authors declare that they have no competing interests.

\section{Authors' contribution}

CXZ and YYB conceived and designed the experiments. YYB analyzed the $N$. lugens genomic and transcriptomic data, and performed the experiments of bacteria-challenge, tissue and development-specific expressions. LYQ conducted the CDNA cloning and sequencing. DZ and LBC performed the experiments of immune effector and CLIP gene expressions. Jin performed the experiments of Toll gene expressions. LMX performed the experiments of PGRP and GRP gene expressions. JAC provided us the valuable suggestions about this work. All authors discussed the results and commented on the manuscript. All authors read and approved the final manuscript.

\section{Acknowledgements}

This work was supported by National Basic Research Program of China (973 Program, No.2010CB126205) and the National Natural Science Foundation of China (Grant no. 31071692, 31070136).

Received: 27 August 2012 Accepted: 28 February 2013

Published: 9 March 2013

\section{Reference}

1. Wilkinson $\mathrm{T}$, Ishikawa $\mathrm{H}$ : On the functional significance of symbiotic microorganisms in the Homoptera: a comparative study of Acyrthosiphon pisum and Nilaparvata lugens. Physiol Entomol 2001, 26(1):86-93.

2. Tang $M, L v L$, Jing $S$, Zhu L, He G: Bacterial symbionts of the brown planthopper, Nilaparvata lugens (Homoptera: Delphacidae). Appl Environ Microbiol 2010, 76(6):1740-1745.

3. Jena KK, Kim SM: Current status of brown planthopper (BPH) resistance and genetics. Rice 2010, 3(2):161-171.

4. Nakashima N, Kawahara N, Omura T, Noda H: Characterization of a novel satellite virus and a strain of Himetobi $P$ virus (Dicistroviridae) from the brown planthopper, Nilaparvata lugens. J Invertebr Pathol 2006, 91(1):53-56.

5. Wang $Y$, Jehle JA: Nudiviruses and other large, double-stranded circular DNA viruses of invertebrates: new insights on an old topic. J Invertebr Pathol 2009, 101(3):187-193.

6. Xue J, Bao YY, Li B, Cheng YB, Peng ZY, Liu H, Xu HJ, Zhu ZR, Lou YG, Cheng JA: Transcriptome analysis of the brown planthopper nilaparvata lugens. PLoS One 2010, 5(12):e14233.

7. Bao YY, Wang Y, Wu WJ, Zhao D, Xue J, Zhang BQ, Shen ZC, Zhang CX: De novo intestine-specific transcriptome of the brown planthopper Nilaparvata lugens revealed potential functions in digestion, detoxification and immune response. Genomics 2012, 99(4):256-264.

8. Yoshida $\mathrm{H}$, Kinoshita K, Ashida M: Purification of a peptidoglycan recognition protein from hemolymph of the silkworm, Bombyx mori. J Biol Chem 1996, 271(23):13854-13860.

9. Morishima I, Yamada K, Ueno T: Bacterial peptidoglycan as elicitor of antibacterial protein synthesis in larvae of the silkworm, Bombyx mori. Insect Biochem Mol Biol 1992, 22(4):363-367.

10. Leulier F, Parquet C, Pili-Floury S, Ryu JH, Caroff M, Lee WJ, Mengin-Lecreulx D, Lemaitre B: The Drosophila immune system detects bacteria through specific peptidoglycan recognition. Nat Immunol 2003, 4(5):478-484.

11. Liu C, Xu Z, Gupta D, Dziarski R: Peptidoglycan recognition proteins. A novel family of four human innate immunity pattern recognition molecules. J Biol Chem 2001, 276(37):34686-34694

12. Mellroth $\mathrm{P}$, Karlsson J, Steiner $\mathrm{H}$ : A scavenger function for DrosophilaPeptidoglycan recognition protein. J Biol Chem 2003, 278(9):7059-7064.

13. Werner T, Liu G, Kang D, Ekengren S, Steiner H, Hultmark D: A family of peptidoglycan recognition proteins in the fruit fly Drosophila melanogaster. Proc Natl Acad Sci 2000, 97(25):13772-13777.
14. Gelius E, Persson C, Karlsson J, Steiner H: A mammalian peptidoglycan recognition protein with $\mathrm{N}$-acetylmuramoyl-alanine amidase activity. Biochem Biophys Res Commun 2003, 306(4):988-994.

15. Royet J, Dziarski R: Peptidoglycan recognition proteins: pleiotropic sensors and effectors of antimicrobial defences. Nat Rev Microbiol 2007, 5(4):264-277.

16. Zaidman-Rémy A, Hervé M, Poidevin M, Pili-Floury S, Kim MS, Blanot D, Oh $\mathrm{BH}$, Ueda R, Mengin-Lecreulx D, Lemaitre B: The Drosophila amidase PGRPLB modulates the immune response to bacterial infection. Immunity 2006, 24(4):463-473.

17. Steiner H: Peptidoglycan recognition proteins: on and off switches for innate immunity. Immunol Rev 2004, 198(1):83-96.

18. Ramsey JS, Rider DS, Walsh TK, De Vos M, Gordon K, Ponnala L, Macmil S, Roe $B$, Jander $G$ : Comparative analysis of detoxification enzymes in Acyrthosiphon pisum and Myzus persicae. Insect Mol Biol 2010, 19:155-164

19. Zaidman-Rémy A, Poidevin M, Hervé M, Welchman DP, Paredes JC, Fahlander C, Steiner H, Mengin-Lecreulx D, Lemaitre B: Drosophila immunity: analysis of PGRP-SB1 expression. Enzymatic Activity and Function. PLoS One 2011, 6(2):e17231.

20. Mellroth PS: H: PGRP-SB1: An N-acetylmuramoyll-alanineamidase with antibacterialactivity. Biochem Biophys Res Commun 2006, 350(4):994-999.

21. Kim MS, Byun M, Oh BH: Crystal structure of peptidoglycan recognition protein LB from Drosophila melanogaster. Nat Immunol 2003 4(8):787-793.

22. Choe KM, Werner T, Stoven S, Hultmark D, Anderson KV: Requirement for a peptidoglycan recognition protein (PGRP) in Relish activation and antibacterial immune responses in Drosophila. Sci STKE 2002, 296(5566):359.

23. Ochiai $M$, Ashida M: Purification of a beta-1, 3-glucan recognition protein in the prophenoloxidase activating system from hemolymph of the silkworm. Bombyx mori. J Biol Chem 1988, 263(24):12056.

24. Kim YS, Ryu JH, Han SJ, Choi KH, Nam KB, Jang IH, Lemaitre B, Brey PT, Lee WJ: Gram-negative bacteria-binding protein, a pattern recognition receptor for lipopolysaccharide and $\beta-1,3$-glucan that mediates the signaling for the induction of innate immune genes in Drosophila melanogaster cells. J Biol Chem 2000, 275(42):32721-32727.

25. Tanaka H, Ishibashi J, Fujita K, Nakajima Y, Sagisaka A, Tomimoto K, Suzuki N Yoshiyama M, Kaneko Y, Iwasaki T: A genome-wide analysis of genes and gene families involved in innate immunity of Bombyx mori. Insect Biochem Mol Biol 2008, 38(12):1087-1110.

26. Gobert V, Gottar M, Matskevich AA, Rutschmann S, Royet J, Belvin M Hoffmann JA, Ferrandon D: Dual activation of the Drosophila toll pathway by two pattern recognition receptors. Sci STKE 2003, 302(5653):2126.

27. Ferrandon D, Imler JL, Hetru C, Hoffmann JA: The Drosophila systemic immune response: sensing and signalling during bacterial and fungal infections. Nat Rev Immunol 2007, 7(11):862-874.

28. Gottar M, Gobert V, Matskevich AA, Reichhart JM, Wang C, Butt TM, Belvin M, Hoffmann JA, Ferrandon D: Dual detection of fungal infections in drosophila via recognition of glucans and sensing of virulence factors. Cell 2006, 127(7):1425-1437.

29. Hoffmann JA: The immune response of Drosophila. Nature 2003 426(6962):33-38.

30. Ochiai M, Ashida M: A pattern-recognition protein for $\beta-1$, 3-glucan. The binding domain and the cDNA cloning of beta-1,3-glucan recognition protein from the silkworm, bombyx mori. J Biol Chem 2000, 275(7):4995-5002.

31. Takahasi K, Ochiai M, Horiuchi M, Kumeta H, Ogura K, Ashida M, Inagaki F: Solution structure of the silkworm $\beta$ GRP/GNBP3 N-terminal domain reveals the mechanism for $\beta-1,3-$ glucan-specific recognition. Proc Natl Acad Sci 2009, 106(28):11679-11684

32. Lemaitre B, Hoffmann J: The host defense of Drosophila melanogaster. Annu Rev Immunol 2007, 25:697-743.

33. Cherry S, Silverman N: Host-pathogen interactions in drosophila: new tricks from an old friend. Nat Immuno/ 2006, 7(9):911-917.

34. Hoffmann JA, Reichhart JM: Drosophila innate immunity: an evolutionary perspective. Nat Immunol 2002, 3(2):121-126.

35. Gregorio DE, Spellman PT, Tzou P, Rubin GM, Lemaitre B: The Toll and Imd pathways are the major regulators of the immune response in Drosophila. EMBO J 2002, 21(11):2568-2579.

36. Hashimoto C, Hudson KL, Anderson KV: The Toll gene of drosophila, required for dorsal-ventral embryonic polarity, appears to encode a transmembrane protein. Cell 1988, 52(2):269-279. 
37. Xu Y, Tao X, Shen B, Horng T, Medzhitov R, Manley JL, Tong L: Structural basis for signal transduction by the Toll/interleukin-1 receptor domains. Nature 2000, 408(6808):111-115.

38. Cheng TC, Zhang YL, Liu C, Xu PZ, Gao Z, Xia QY, Xiang ZH: Identification and analysis of Toll-related genes in the domesticated silkworm, Bombyx mori. Dev Comp Immunol 2008, 32(5):464-475.

39. Söderhäll I, Wu C, Novotny M, Lee BL, Söderhäll K: A novel protein acts as a negative regulator of prophenoloxidase activation and melanization in the freshwater crayfish Pacifastacus leniusculus. J Biol Chem 2009, 284(10):6301-6310.

40. Cerenius L, Kawabata S, Lee BL, Nonaka M, Soderhall K: Proteolytic cascades and their involvement in invertebrate immunity. Trends Biochem Sci 2010, 35(10):575-583.

41. Kanost M, Clarke T: Proteases. Comprehensive molecular insect science 2005 4:247-266

42. Jiang $H$, Wang $Y, Y u X Q$, Zhu $Y$, Kanost M: Prophenoloxidase-activating proteinase-3 (PAP-3) from Manduca sexta hemolymph: a clip-domain serine proteinase regulated by serpin- $1 \mathrm{~J}$ and serine proteinase homologs. Insect Biochem Mol Biol 2003, 33(10):1049-1060.

43. Bao $Y$, Yamano $Y$, Morishima I: $\beta-1,3-$-Glucan inducible expression of prophenoloxidase-activating proteinase from eri-silkworm, Samia cynthia ricini. Comp Biochem Physiol B Biochem Mol Biol 2007, 147(1):45-48.

44. Jiang $\mathrm{H}$, Kanost MR: The clip-domain family of serine proteinases in arthropods. Insect Biochem Mol Biol 2000, 30(2):95.

45. Satoh D, Horii A, Ochiai M, Ashida M: Prophenoloxidase-activating enzyme of the silkworm, Bombyx mori. J Biol Chem 1999, 274(11):7441-7453.

46. Cerenius L, Lee BL, Söderhäll K: The proPO-system: pros and cons for its role in invertebrate immunity. Trends Immunol 2008, 29(6):263-271.

47. De Gregorio E, Han SJ, Lee WJ, Baek MJ, Osaki T, Kawabata SI, Lee BL, Iwanaga S, Lemaitre B, Brey PT: An immune-responsive Serpin regulates the melanization cascade in Drosophila. Dev Cell 2002, 3(4):581-592.

48. Kanost MR, Jiang $H$, Yu XQ: Innate immune responses of a lepidopteran insect, Manduca sexta. Immunol Rev 2004, 198(1):97-105.

49. Tong $Y$, Kanost MR: Manduca sexta serpin- 4 and serpin- 5 inhibit the prophenol oxidase activation pathway. J Biol Chem 2005, 280(15): 14923-14931.

50. Tong $Y$, Jiang $H$, Kanost MR: Identification of plasma proteases inhibited by Manduca sexta serpin- 4 and serpin- 5 and their association with components of the prophenol oxidase activation pathway. J Biol Chem 2005, 280(15):14932-14942.

51. Aggarwal K, Silverman N: Positive and negative regulation of the Drosophila immune response. BMB Rep 2008, 41(4):267-277.

52. Gandhe AS, John SH, Nagaraju J: Noduler, a novel immune up-regulated protein mediates nodulation response in insects. J Immuno/ 2007 179(10):6943.

53. Zhu Y, Johnson TJ, Myers AA, Kanost MR: Identification by subtractive suppression hybridization of bacteria-induced genes expressed in Manduca sexta fat body. Insect Biochem Mol Biol 2003, 33(5):541-559.

54. Shin SW, Park SS, Park DS, Kim MG, Kim SC, Brey PT, Park HY: Isolation and characterization of immune-related genes from the fall webworm, Hyphantria cunea, using PCR-based differential display and subtractive cloning. Insect Biochem Mol Biol 1998, 28(11):827-837.

55. Bao Y, Mega K, Yamano Y, Morishima I: cDNA cloning and expression of bacteria-induced Hdd11 gene from eri-silkworm, Samia cynthia ricini. Comp Biochem Physiol C Toxicol Pharmacol 2003, 136(4):337-342.

56. Veiga AB, Ribeiro JM, Guimaraes JA, Francischetti IM: A catalog for the transcripts from the venomous structures of the caterpillar Lonomia obliqua: identification of the proteins potentially involved in the coagulation disorder and hemorrhagic syndrome. Gene 2005, 355:11-27.

57. Bao Y, Xue J, Wu W, Wang Y, Lv Z, Zhang C: An immune-induced reeler protein is involved in the Bombyx mori melanization cascade. Insect Biochem Mol Biol 2011, 41(9):696.

58. Callewaert L, Michiels CW: Lysozymes in the animal kingdom. J BiosCi 2010, 35(1):127-160

59. Zou H, Song L, Xu W, Yang G: Molecular cloning and characterization analysis of cDNA encoding g-type lysozyme from scallop (Argopecten irradians). High Tech Lett 2005, 15:101-106.

60. Zhao J, Song L, Li C, Zou H, Ni D, Wang W, Xu W: Molecular cloning of an invertebrate goose-type lysozyme gene from Chlamys farreri, and lytic activity of the recombinant protein. Mol Immunol 2007, 44(6):1198-1208.
61. Irwin DM, Gong ZM: Molecular evolution of vertebrate goose-type lysozyme genes. J Mol Evol 2003, 56(2):234-242.

62. Nilsen I, Myrnes B, Edvardsen R, Chourrout D: Urochordates carry multiple genes for goose-type lysozyme and no genes for chicken-or invertebrate-type lysozymes. Cell Mol Life Sci 2003, 60(10):2210-2218.

63. Li B, Calvo E, Marinotti O, James AA, Paskewitz SM: Characterization of the c-type lysozyme gene family in Anopheles gambiae. Gene 2005, 360(2):131-139.

64. Paskewitz S, Li B, Kajla M: Cloning and molecular characterization of two invertebrate--type lysozymes from Anopheles gambiae. Insect Mol Biol 2008, 17(3):217-225.

65. Ito Y, Yoshikawa A, Hotani T, Fukuda S, Sugimura K, Imoto T: Amino acid sequences of lysozymes newly purified from invertebrates imply wide distribution of a novel class in the lysozyme family. Eur J Biochem 1999, 259(1-2):456-461.

66. Itoh N, Takahashi KG: CDNA cloning and in situ hybridization of a novel lysozyme in the Pacific oyster, Crassostrea gigas. Comp Biochem Physiol B Biochem Mol Biol 2007, 148(2):160-166.

67. Xue QG, Itoh N, Schey K, Li YL, Cooper R, La Peyre J: A new lysozyme from the eastern oyster (Crassostrea virginica) indicates adaptive evolution of i-type lysozymes. Cell Mol Life Sci 2007, 64(1):82-95.

68. Olsen OM, Nilsen IW, Sletten K, Myrnes B: Multiple invertebrate lysozymes in blue mussel (Mytilus edulis). Comp Biochem Physiol B Biochem Mol Biol 2003, 136(1):107-115.

69. Zavalova L, Baskova I, Lukyanov S, Sass A, Snezhkov E, Akopov S, Artamonova I, Archipova V, Nesmeyanov V, Kozlov D: Destabilase from the medicinal leech is a representative of a novel family of lysozymes. Biochimica et Biophysica Acta (BBA)-Protein Structure and Molecular Enzymology 2000, 1478(1):69-77.

70. Touch V, Hayakawa S, Saitoh K: Relationships between conformational changes and antimicrobial activity of lysozyme upon reduction of its disulfide bonds. Food Chem 2004, 84(3):421-428.

71. Zavalova L, Yudina T, Artamonova I, Baskova I: Antibacterial nonglycosidase activity of invertebrate destabilase-lysozyme and of its helical amphipathic peptides. Chemotherapy 2006, 52(3):158-160.

72. Cong L, Yang X, Wang X, Tada M, Lu M, Liu H, Zhu B: Characterization of an i-type lysozyme gene from the sea cucumber Stichopus japonicus, and enzymatic and nonenzymatic antimicrobial activities of its recombinant protein. J Biosci Bioeng 2009, 107(6):583-588.

73. Consortium IAG: Genome sequence of the pea aphid Acyrthosiphon pisum. PLOS Biol 2010, 8(2):e1000313.

74. Kocks C, Cho JH, Nehme N, Ulvila J, Pearson AM, Meister M, Strom C, Conto SL, Hetru C, Stuart LM: Eater, a transmembrane protein mediating phagocytosis of bacterial pathogens in drosophila. Cell 2005, 123(2):335-346.

75. Thompson JD, Gibson TJ, Plewniak F, Jeanmougin F, Higgins DG: The CLUSTAL X windows interface: flexible strategies for multiple sequence alignment aided by quality analysis tools. Nucleic Acids Res 1997 25(24):4876-4882

doi:10.1186/1471-2164-14-160

Cite this article as: Bao et al:: The genome- and transcriptome-wide analysis of innate immunity in the brown planthopper, Nilaparvata lugens. BMC Genomics 2013 14:160

\section{Submit your next manuscript to BioMed Central and take full advantage of:}

- Convenient online submission

- Thorough peer review

- No space constraints or color figure charges

- Immediate publication on acceptance

- Inclusion in PubMed, CAS, Scopus and Google Scholar

- Research which is freely available for redistribution 